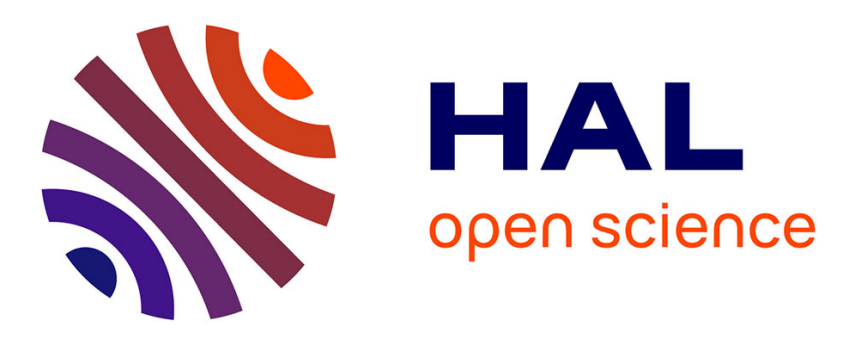

\title{
Experimental and Theoretical Study of the Reactivity of Gold Nanoparticles towards Benzimidazole-2-ylidene Ligands
}

\author{
María Rodríguez-Castillo, Gustavo Lugo-Preciado, Danielle Laurencin,
} Frederik Tielens, Arie Van der lee, Sébastien Clément, Yannick Guari, José M. López-De-Luzuriaga, Miguel Monge, Françoise Remacle, et al.

\section{To cite this version:}

María Rodríguez-Castillo, Gustavo Lugo-Preciado, Danielle Laurencin, Frederik Tielens, Arie Van der lee, et al.. Experimental and Theoretical Study of the Reactivity of Gold Nanoparticles towards Benzimidazole-2-ylidene Ligands. Chemistry - A European Journal, 2016, 22 (30), pp.10680. 10.1002/chem.201602146 . hal-01333959

\section{HAL Id: hal-01333959 \\ https://hal.sorbonne-universite.fr/hal-01333959}

Submitted on 20 Jun 2016

HAL is a multi-disciplinary open access archive for the deposit and dissemination of scientific research documents, whether they are published or not. The documents may come from teaching and research institutions in France or abroad, or from public or private research centers.
L'archive ouverte pluridisciplinaire HAL, est destinée au dépôt et à la diffusion de documents scientifiques de niveau recherche, publiés ou non, émanant des établissements d'enseignement et de recherche français ou étrangers, des laboratoires publics ou privés. 


\title{
Experimental and Theoretical Study of the Reactivity of Gold Nanoparticles Towards Benzimidazole-2-ylidene Ligands
}

\author{
María Rodríguez-Castillo, ${ }^{[\mathrm{a}]}$ Gustavo Lugo-Preciado, ${ }^{[\mathrm{b}]}$ Danielle Laurencin, ${ }^{[\mathrm{a}]}$ Frederik Tielens, ${ }^{,[\mathrm{c}]}$ Arie \\ van der Lee, ${ }^{[\mathrm{d}]}$ Sébastien Clément, ${ }^{[a]}$ Yannick Guari, ${ }^{[\mathrm{a}]}$ José M. López-de-Luzuriaga, ${ }^{[\mathrm{e}]}$ Miguel Monge, ${ }^{[\mathrm{e}]}$ \\ Françoise Remacle ${ }^{*[b]}$ and Sébastien Richeter ${ }^{\star[a]}$
}

\begin{abstract}
The purpose of this work is to shed light on the reactivity of benzimidazol-2-ylidenes with respect to gold nanoparticles (AuNPs), using a combined experimental/computational approach. First, the grafting of benzimidazol-2-ylidenes bearing benzyl groups on the nitrogen atoms is described, and comparisons are made with structurally similar $\mathrm{N}$-heterocyclic carbenes (NHCs) bearing other $\mathrm{N}$ groups. Similar reactivity was observed for all NHCs, with (I) the erosion of the AuNPs under the effect of the NHC and (ii) the formation of bis(NHC) gold complexes. Density Functional Theory (DFT) calculations were performed to investigate the modes of grafting of such ligands, and to determine adsorption energies. Two types of computational models were developed, in order to describe the grafting onto large or small AuNPs, using either periodic or cluster-type DFT calculations. Calculations of NMR parameters were also performed on some of these models, and discussed in light of the experimental data.
\end{abstract}

\section{Introduction}

Metal nanoparticles (MNPs) are an important class of nanomaterials which have found numerous applications, notably in catalysis $^{[1]}$ and medicine. ${ }^{[2]}$ During the last decade, many synthetic pathways have been reported to obtain MNPs of controlled size and shape, both of these criteria being very important for specific applications like catalysis. ${ }^{[1]}$ As well documented in the literature, the nature of the coating agents

[a] Dr. M. Rodríguez-Castillo, Dr. D. Laurencin, Dr. S. Clément, Dr. Y. Guari, Dr. S. Richeter

Institut Charles Gerhardt, UMR 5253 CNRS-ENSCM-UM

Université de Montpellier, CC 1701, Place E. Bataillon,

34095 Montpellier Cedex 05, France

E-mail: sebastien.richeter@umontpellier.fr

[b] G. Lugo-Preciado, Dr. F. Remacle

Chemistry Department, B6c, University of Liège

4000 Liège, Belgium

E-mail: fremacle@ulg.ac.be

[c] Dr. F. Tielens

Sorbonne Université, UPMC Université Paris 06, UMR 7574 Laboratoire Chimie de la Matière Condensée de Paris, Collège de France, 11 place M. Berthelot, 75231 Paris Cedex 05, France E-mail: frederik.tielens@upmc.fr

[d] Dr. A. van der Lee

Institut Européen des Membranes UMR 5635 CNRS-ENSCM-UM Université de Montpellier, Place E. Bataillon, 34095 Montpellier Cedex 05, France

[e] Dr. José M. López-de-Luzuriaga, Dr. M. Monge Departamento de Química, Universidad de La Rioja, Grupo de Síntesis Química de la Rioja, UA-CSIC, Complejo CientíficoTecnológico, 26004-Logroño, Spain

Supporting information for this article is available on the WWW under http://www.chemeurj.org/ or from the author. and experimental conditions used for the synthesis of MNPs have a significant impact on their morphology and solubility. ${ }^{[3]}$

$\mathrm{N}$-Heterocyclic carbenes (NHCs) have become an ubiquitous class of ligands in the field of organometallic chemistry. ${ }^{[4]}$ As NHCs are singlet carbenes, they are considered as phosphine analogs (i.e. two-electron $\sigma$-donor ligands), which can form very stable bonds with a wide range of metals in low and high oxidation states, including noble metals like $\mathrm{Ru}^{[5]} \mathrm{Pd}^{[6]}$ or $\mathrm{Au}^{\left[{ }^{[7]}\right.}$ Since their steric and electronic properties can be finely tuned according to the substituents present, respectively, on the nitrogen atoms and heterocycle backbone, NHCs are now extensively used in the field of catalysis either as ligands of transition-metal complexes ${ }^{[4]}$ or as organocatalysts. ${ }^{[8]}$ The use of $\mathrm{NHCs}$ as coating and stabilizing agents of metal nanoparticles (MNPs), and more generally metal surfaces, is also an emerging field of research with promising applications. NHC-coated $\mathrm{Pd}^{\left[{ }^{[9]}\right.}$ $\mathrm{Ag},{ }^{[10]} \mathrm{Ru}^{[11]}$ and $\mathrm{Pt}^{[12]}$ nanoparticles have indeed been described in the literature: it was shown that these NHC-coated MNPs are often stable, and that they can sometimes be used as catalysts. ${ }^{[9,11,12]}$

Among MNPs, gold nanoparticles (AuNPs) are probably one of the most investigated metal-based nanoparticles. ${ }^{[13-17]}$ Surface stabilization of AuNPs is routinely performed with thiols. ${ }^{[13]}$ However, more labile ligands such as thioethers, ${ }^{[14]}$ phosphines, ${ }^{[15]}$ amines,${ }^{[16]}$ or carboxylate ${ }^{[17]}$ can also be used. In the last few years, the use of NHCs to stabilize AuNPs has also been looked into. ${ }^{[9 b, 18-25]}$ The stability of NHC-coated AuNPs strongly depends of the structure of the NHCs, i.e. their size and their rigidity: in order to ensure an efficient stabilization, they should be small or flexible to minimize steric repulsion between the NHC and the AuNP surface. In particular, small groups such as methyls or long flexible alkyl chains are suitable $\mathrm{N}$ substituents. More surprisingly, the stability of NHC-coated AuNPs strongly depends on the experimental procedures used for their synthesis. To date, stable AuNPs coated by NHCs have mainly been prepared by chemical reduction ${ }^{[18,19]}$ or thermolysis ${ }^{[20]}$ of molecular species. Preparations using ligand exchange reactions have also been reported. In this case, starting materials are AuNPs coated by weakly coordinated molecules such as thioethers. Chechik et al. showed that the substitution of thioethers by NHCs is feasible, but they observed that the obtained AuNPs were not very stable and aggregated within a few hours. ${ }^{[11]}$ In contrast, Glorius, Ravvo et al. showed that stable NHC-coated MNPs ( $\mathrm{M}=\mathrm{Au}$ or $\mathrm{Pd}$ ) could be obtained by ligand exchange reactions using $\mathrm{NHCs}$ bearing long alkyl chains at their backbone (in positions 3 and 4 of imidazol-2ylidenes).$^{[9 b]}$ The improved stability of the NHC-coated AuNPs can be explained by the chemisorption of the NHC at the AuNPs surface and by the interactions between the long alkyl chains which occur simultaneously. ${ }^{[9 b, 19]}$ 
To date, most studies on the functionalization of AuNPs by $\mathrm{NHCs}$ have been performed using imidazol-2-ylidenes. However, in order to have a better comprehension of the interaction between NHCs and AuNPs, and to extend the types of coating agents which could be used, we, and others, have more recently started to study benzimidazol-2-ylidenes as stabilizing agents of AuNPs. ${ }^{[19,22,23]}$ Crudden et al. showed that stable self-assembled monolayers of benzimidazol-2-ylidenes can be anchored on planar gold surfaces by exchange of thioether molecules. ${ }^{[22]}$ In comparison to imidazol-2-ylidenes, the presence of the benzene ring fused to the positions 3 and 4 thus appears as a suitable option for further stabilization through $\pi-\pi$ stacking at the surface of AuNPs. These additional inter-NHCs interactions seem to be of importance to obtain stable NHC-coated planar gold surfaces. Concurrently, we demonstrated that ligand exchange reactions between thioethers and benzimidazol-2-ylidenes bearing methyl or $n$-hexyl groups on the $\mathrm{N}$ atoms (Figure 1, NHCa and $\mathbf{N H C b}$ ) occurred at the surface of AuNPs, ${ }^{[23]}$ and ${ }^{13} \mathrm{C}$ solid state NMR spectroscopy was used to characterize the grafted NHCs. We also showed that the reactivity of these benzimidazol-2-ylidenes was actually complex, because in addition to the ligand exchange reaction, the formation of bis $(\mathrm{NHC}) \mathrm{Au}(\mathrm{I})$ complexes was clearly evidenced (Figure 1, 3a and $\mathbf{3 b}$ ). Moreover, Au(I) complexes used as starting materials or generated during the reaction also appeared to be able to remove thioether molecules from the surface of AuNPs. ${ }^{[22]}$
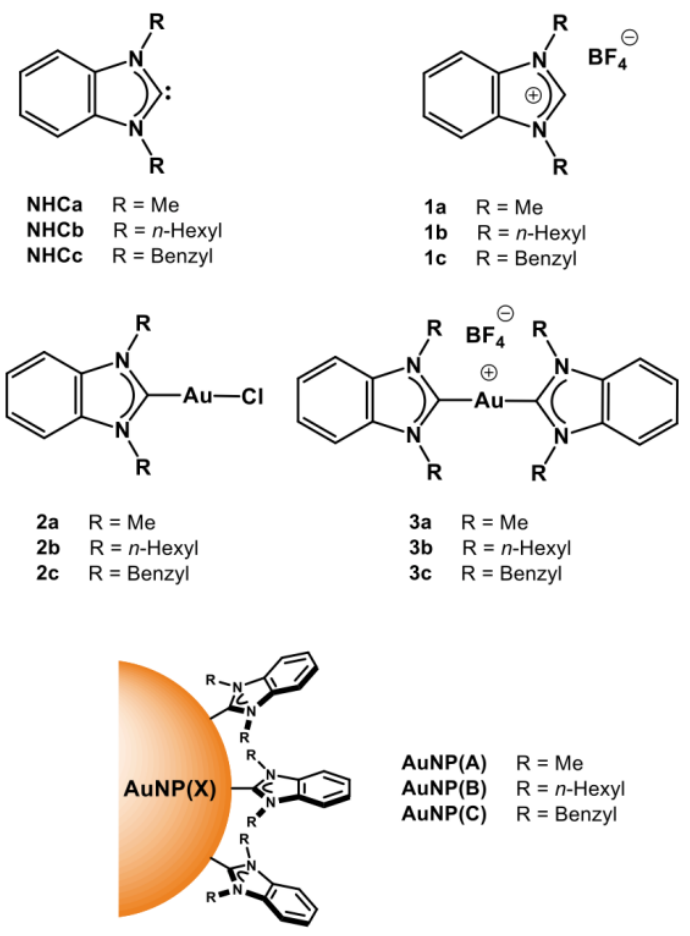

Figure 1. Structure of the NHC ligands, benzimidazolium salts, NHC-Au(I) complexes, and NHC-functionalized AuNPs discussed in this work.
Due to the apparent complexity of the reactivity of NHCs towards Au surfaces, and given the difficulties in characterizing experimentally their exact mode of grafting, computational studies have been initiated. ${ }^{[22,23,25]}$ In particular, Density Functional Theory (DFT) calculations have been carried out using both periodic ${ }^{[22,23]}$ and cluster approaches. ${ }^{[22,25]}$ To date, these computational studies have mainly been performed in order to gain insight into the nature of binding between the $\mathrm{NHC}$ and the Au surface, and to calculate the binding energy of the $\mathrm{NHC}$ ligand. However, the calculations have so far been carried out on relatively simple models of Au surfaces, meaning that more complex simulations still need to be performed to get a better grasp of the potential differences in binding of NHCs on different Au surfaces, and hence, on AuNPs of different size and shape.

The purpose of this work is thus to provide a deeper insight into the reactivity and the grafting of benzimidazol-2ylidenes at AuNP surfaces. In a first part, an overview of the experimental observations concerning the reactivity of benzimidazol-2-ylidenes onto AuNPs is provided. In particular, the grafting of a carbene bearing benzyl groups on the $\mathrm{N}$ atoms (NHCc) is discussed. Benzyl groups were chosen because they are flexible substituents which may contribute to further stabilize AuNPs through $\pi$-interactions with the gold surface. ${ }^{[11 a, 25]}$ Here, the reactivity of this new system is compared with the previously studied NHCs involving methyl or $n$-hexyl substituents (NHCa and $\mathbf{N H C b}$, respectively), ${ }^{[23]}$ and the challenges related to the characterization of the functionalized nanoparticles are underscored. In a second part, a computational study of the binding of benzimidazol-2-ylidene ligands at AuNP surfaces is provided through DFT calculations. Different approaches (periodic and finite model DFT) to the modeling of gold surfaces functionalized by benzimidazol-2-ylidenes are presented, by looking at their grafting either onto "flat" Au surfaces or onto small nanoparticles, providing complementary insight into the strength and mode of binding benzimidazol-2-ylidenes on $\mathrm{Au}$ surfaces. In the latter case, DFT calculations of NMR parameters were also performed, and results were discussed in view of the experimental data.

\section{Results and Discussion}

1. Reactivity of NHCc towards thioether-coated AuNPs. The starting AuNPs used for the grafting were synthesized following the procedure described by Reinhoudt et al. ${ }^{[2]}$ They are well-dispersed spherical AuNPs coated with di- $n$ dodecylthioether, and have a mean size of $5.8( \pm 1.2) n m .{ }^{[23]}$ The grafting of NHCc was performed in a similar way as previously described for $\mathbf{N H C a}$ and $\mathbf{N H C b}{ }^{[23]}$ First, the di- $n$ dodecylthioether-coated AuNPs were mixed with the benzimidazolium salt 1c. Then, $t \mathrm{BuONa}$ was added to deprotonate 1c and generate NHCc in situ. This led to the quick appearance of a dark precipitate in the reaction medium. Before complete precipitation, the UV-visible spectrum of the suspension was collected, in order to monitor the change in the Surface Plasmon Resonance (SPR) of the AuNPs. Compared to 
the spectrum of the starting di- $n$-dodecylthioether coated AuNPs $\left(\lambda_{\max } \sim 510 \mathrm{~nm}\right)$, SPR absorption band of the crude AuNPs(C) was bathochromically shifted to $\lambda_{\max } \sim 520 \mathrm{~nm}$, suggesting that NHC-coated nanoparticles tend to aggregate.

A/

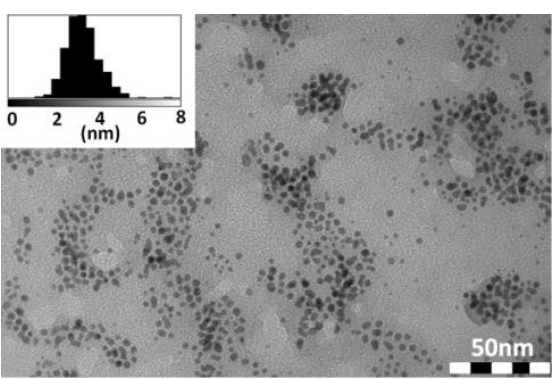

B/

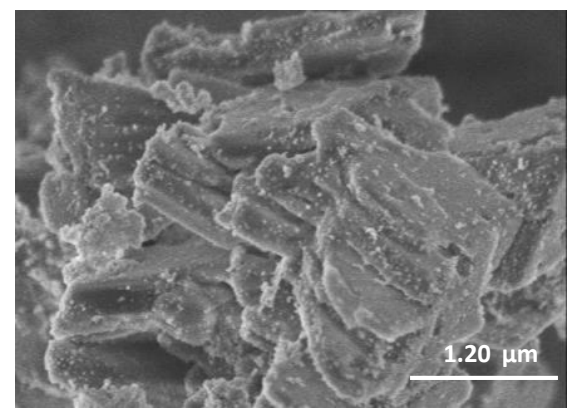

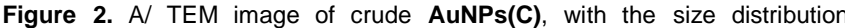
histogram (statistics over $408 \mathrm{NPs}$; $\min .=1.39 \mathrm{~nm}$; $\max =7.48 \mathrm{~nm}$; mean = $3.44 \mathrm{~nm}$; standard deviation $=0.77 \mathrm{~nm}$ ); B/ SEM image of crude AuNPs(C) after precipitation with $\mathrm{EtOH}$.

Transmission electron microscopy (TEM) analyses actually show that the crude $\operatorname{AuNPs}(\mathbf{C})$ contain both aggregated and well dispersed spherical NPs, with a mean size of $3.4( \pm 0.8) \mathrm{nm}$ (Figure 2A). Thus, there is a significant decrease in the average size of the nanoparticles compared to the starting thioethercoated AuNPs $(5.8( \pm 1.2) \mathrm{nm})$. A similar observation had been made in the case of $\mathbf{N H C a}$, for which an average size of 2.8 $( \pm 0.6) \mathrm{nm}$ had been measured for the crude $\operatorname{AuNPs}(\mathbf{A}) \cdot{ }^{[23]} \mathrm{In}$ contrast, in the case of $\mathbf{N H C b}$, the crude $\operatorname{AuNPs}(\mathbf{B})$ had an average particle size $\sim 5.1( \pm 1.0) \mathrm{nm}$, which is more similar to the starting AuNPs. ${ }^{[23]}$ This is probably due to the presence of long alkyl chains on the nitrogen atoms of $\mathbf{N H C b}$, which interact better with each other, and thereby improve the stability of the NHC-coated AuNPs, and prevent a surface etching process to occur. Such results are consistent with the work recently reported by Glorius, Ravvo et al. ${ }^{[\mathrm{b}]}$

Crude $\operatorname{AuNPs(C)}$ were precipitated by addition of ethanol, and isolated after several cycles of centrifugation and washing. Scanning electronic microscopy (SEM) showed the presence of a crystalline phase in the precipitate (Figure 2B), which was identified by powder XRD and ${ }^{13} \mathrm{C}$ solid state NMR (Figure 3 ). Indeed, when comparing the diffractogram of the crude $\operatorname{AuNPs}(\mathbf{C})$ to those of the benzimidazolium salt 1c, and of the $\mathrm{NHCc}-\mathrm{Au}(\mathrm{I})$ complexes $\mathbf{2 c}$ and $\mathbf{3 c}$ (for which a full description of the crystal structures and spectral data is provided in the Supporting Information), it is clear that the bis(NHC) $\mathrm{Au}(\mathrm{I})$ complex $\mathbf{3 c}$ is the crystalline by-product. It is worth noting that the presence of AuNPs in the crude $\operatorname{AuNPs(C)}$ sample is actually hardly noticeable by $\mathrm{XRD}$, due to the high quantity and high crystallinity of $3 c$ : only a weak Bragg reflection around $2 \theta \sim$ $40^{\circ}$, characteristic of the (111) reflection of $\mathrm{Au}$ is visible (Figure $3 \mathrm{~A})$. The analysis of the ${ }^{13} \mathrm{C}$ CPMAS (Cross-Polarization Magic Angle Spinning) solid state NMR spectrum of the crude $\operatorname{AuNPs}(\mathbf{C})$ was also consistent with the formation of the bis(NHC) $\mathrm{Au}(\mathrm{I})$ complex $3 \mathrm{c}$, as shown by the characteristic chemical shift at $\sim 190 \mathrm{ppm}$ of the carbon bound to $\mathrm{Au}(\mathrm{I})$ (data not shown). ${ }^{[23,28]}$ Thus, both XRD and ${ }^{13} \mathrm{C}$ solid state NMR suggest that the etching of the AuNPs is related to the formation of the bis(NHC) $A u(I)$ complex 3c. The results are fully consistent with our previous study on the grafting of $\mathrm{NHCa}$ and NHCb on AuNPs. ${ }^{[23]}$

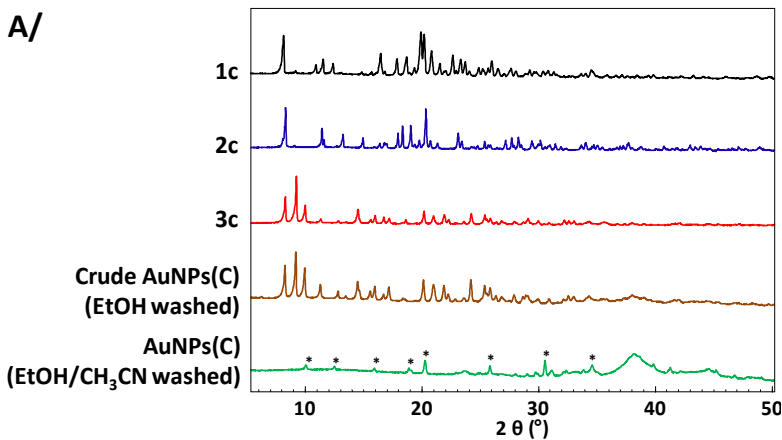

B/

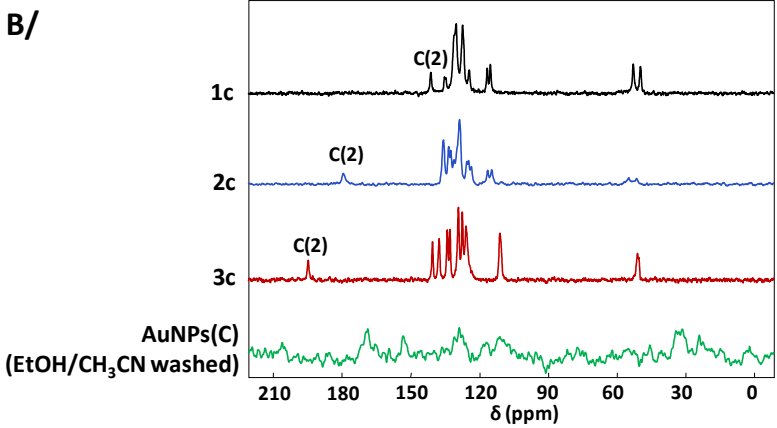

Figure 3. A/ XRD powder patterns of compounds 1c, 2c, 3c, crude AuNPs(C) and $\operatorname{AuNPs}(\mathbf{C})$ after additional washing with $\mathrm{CH}_{3} \mathrm{CN}$; ( ${ }^{*}$ reflections assigned to $\mathrm{Na}_{2} \mathrm{~B}_{4} \mathrm{O}_{7}{ }^{*} 5 \mathrm{H}_{2} \mathrm{O}$, a by-product formed during the reaction). $\mathrm{B} /{ }^{13} \mathrm{C}$ CPMAS solid state NMR spectra of $\mathbf{1 c}, \mathbf{2 c}, \mathbf{3 c}$, and $\operatorname{AuNPs}(\mathbf{C})$ after washing with $\mathrm{EtOH}$ and $\mathrm{CH}_{3} \mathrm{CN}$.

Given that the bis(NHC) $\mathrm{Au}(\mathrm{I})$ complex $3 \mathrm{c}$ was soluble in acetonitrile, it was possible to wash the crude $\operatorname{AuNPs}(\mathbf{C})$ with this solvent to isolate the functionalized nanoparticles. These NPs were found to be insoluble in most solvents, and they were thus characterized by ${ }^{13} \mathrm{C}$ CPMAS solid state NMR in order to identify organic species such as NHCs at their surface. Several difficulties were encountered when trying to record the ${ }^{13} \mathrm{C} N M R$ 
spectrum. Indeed, because several washes were needed to fully eliminate the diffraction peaks corresponding to the bis $(\mathrm{NHC})$ $\mathrm{Au}(\mathrm{I})$ complex, only a very small amount of residual NPs was collected. The solid state NMR spectrum obtained on these NPs was very noisy, even after two days of acquisition (Figure 3B, green spectrum). Nevertheless, signals characteristic of NHCc can be distinguished on this spectrum, proving their presence at the AuNPs surface. It is worth noting that in our previous work, difficulties had also been encountered for recording the ${ }^{13} \mathrm{C}$ solid state NMR spectra of the grafted NPs after complete washing, notably for AuNPs functionalized by $\mathbf{N H C a} .{ }^{[23]}$ So far, it is only in the case of $\mathbf{N H C b}$ ligands that a decent spectrum could be obtained, with broad signals and different chemical shifts for the carbene $C(2)$ atom (at $\delta \sim 170$ and $181 \mathrm{ppm}) .{ }^{[23]}$

2. Modeling of functionalized AuNPs. As shown above, the characterization of the exact mode of grafting of NHCs at the surface of AuNPs can be particularly challenging, especially when the surface coverage of the nanoparticles is low. Thus, in view of clarifying in a more general way the interaction between benzimidazol-2-ylidene carbenes and AuNP surfaces, computational modeling was performed using DFT calculations. Given that NHCs have been shown to be able to bind to AuNPs of different size (ranging from $\sim 1$ to $6.8 \mathrm{~nm}$ ), ${ }^{[18,19,23]}$ two different approaches were used to model the grafting. On one hand, the functionalization of the larger AuNPs was modeled considering a planar $\mathrm{Au}(111)$ surface, since it is predominant in relatively large AuNPs, as consequence of being the most stable surface. ${ }^{[29]}$ In this case, periodic DFT calculations were performed using the VASP code. ${ }^{[29]}$ On the other hand, the functionalization of the smaller AuNPs was modeled considering the $\mathrm{Au}_{38}$ gold cluster, which is a well-known Au cluster with a size of $\sim 1 \mathrm{~nm} \cdot{ }^{[30]}$ In this case, calculations were performed using a cluster-type approach and the Gaussian09 code. $^{[31]}$ For both kinds of DFT investigations, the grafting of the benzimidazol-2-ylidene carbene bearing a methyl substituent on the nitrogen atoms (NHCa) was studied in order to reduce the computational cost, and because our experimental studies had shown similar reactivity for $\mathbf{N H C a}, \mathbf{N H C b}$ and $\mathbf{N H C c}$.

Grafting of $\mathrm{NHCa}$ on a planar Au(111) surface. The binding of a single NHCa ligand on a planar $\mathrm{Au}(111)$ surface was first studied. Only monodentate modes of coordination of the $\mathrm{NHC}$ at the Au surface were considered (through a single $\mathrm{Au}-\mathrm{C}(2)$ bond), because a previous computational study had shown that it was energetically less favorable for the carbene to adopt bridging positions between surface $\mathrm{Au}$ atoms. ${ }^{[22]}$ Here, different binding orientations with respect to the surface were studied for NHCa (Figure 4): perpendicular (Model A), tilted by $\sim 5^{\circ}$ (Model B) and parallel (Model C). Looking at the orientation preference of the carbene at the $\mathrm{Au}(111)$ surface appeared as an important point to consider, because a recent computational investigation on the grafting of pyridine derivatives on Au had shown that depending on the nature of the substituents on the pyridine, either parallel or perpendicular configurations could be more favourable. ${ }^{[32]}$ In the case of $\mathbf{N H C a}$ the energies of these different configurations after geometry optimization are provided in Table 1, together with the average $\mathrm{Au}-\mathrm{C}(2)$ distances.

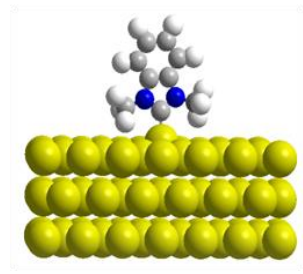

Model A

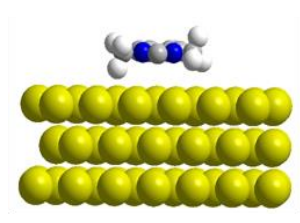

Model C

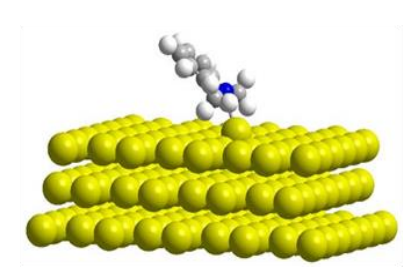

Model B

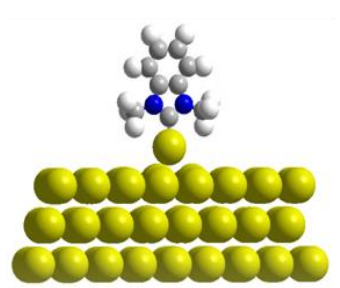

Model D
Figure 4. DFT-optimized geometries for the different grafting models of NHCa on the $\mathrm{Au}(111)$ surface (VASP code).

Results presented in Table 1 clearly show that the perpendicular binding of $\mathrm{NHCa}$ with respect to the $\mathrm{Au}(111)$ surface (Model A) is more favourable than the other geometries, the adsorption energy being $\sim-34.21 \mathrm{kcal} \cdot \mathrm{mol}^{-1}$. Compared to Model B where $\mathbf{N H C a}$ is not perpendicular to the surface, the energy difference is small $\left(\sim 3.76 \mathrm{kcal}^{\mathrm{mol}}{ }^{-1}\right)$ suggesting that the angle is flexible and determined by the surface coverage. However, a closer look at the geometries of the optimized structures suggests that this may be because the perpendicular orientation represents the optimal balance between intermolecular interactions between the methyl substituents and the Au surface (dispersion - steric repulsion), and the best Au$\mathrm{C}(2)$ orbital overlap. It is worth noting that in Models $\mathbf{A}$ and $\mathbf{B}$, the $A u$ atom is pulled up out of the surface by $\sim 1 \AA$, and the $A u-$ $\mathrm{C}$ (2) distance is $\sim 2.1 \AA$, which is similar to what is observed in mono(NHC) and bis(NHC) $\mathrm{Au}(\mathrm{l})$ complexes like $2 \mathrm{a}(\mathrm{d}(\mathrm{Au}-\mathrm{C}(2))$ $\sim 1.98 \AA)^{[33]}$ and $3 a(\mathrm{~d}(\mathrm{Au}-\mathrm{C}(2)) \sim 2.01 \AA) .{ }^{[23]}$ This confirms that strong $A u-C(2)$ bonds can form between the Au surface and the carbene. A similar phenomenon has been observed for other ligands such as thiols, for which the alkyl chain length can also influence the $\mathrm{Au}-\mathrm{S}$ bond length. ${ }^{[34]}$ In contrast, when the adsorption of a thioether ligand like diethylthioether on $\mathrm{Au}(111)$ was considered (as a model of the di- $n$-dodecylthioether ligand initially present experimentally at the surface of the AuNPs), a much weaker adsorption energy $\left(\sim-14.36 \mathrm{kcal}^{\mathrm{mol}}{ }^{-1}\right)$ and a longer Au-S bond $(\sim 2.60 \AA)$ were observed, which explains the ease with which these ligands could be removed from the surface during the synthesis (Figure $\mathrm{S} 12$ in the Supporting Information).

It should be noted that the pulling of a gold atom out of the surface in Models A and B can only be seen as a local minimum on the potential energy surface, without passing a 
possible activation energy barrier for the formation of a true adatom, and without introducing the filling up of the vacancy site left in the bulk after displacement of this gold atom on top of the surface. However, the present optimized geometries might be considered as the initial step of a surface reconstruction induced by grafting of a carbene. Such pulling of a Au atom out of the surface might also facilitate the release of mono( $\mathrm{NHC}) \mathrm{Au}(\mathrm{I})$ complexes, and thereby explain the formation of bis(NHC) $\mathrm{Au}(\mathrm{I})$ complexes such as $\mathbf{3 a - c}$ (vide infra).

Table 1. Binding energies and $\mathrm{Au}-\mathrm{C}(2)$ bond lengths for the optimized Models A-D (VASP code)

\begin{tabular}{ccc}
\hline Model & $\begin{array}{c}\text { Binding energy } \\
\left(\text { kcal.mol }^{-1}\right)\end{array}$ & Au-C(2) distance $(\AA)$ \\
\hline Model A & -34.21 & 2.10 \\
Model B & -30.45 & 2.11 \\
Model C & -11.42 & 2.40 \\
Model D & -63.55 & 2.03 \\
\hline
\end{tabular}

The grafting of NHCa onto an adatom positioned at a facecentered cubic (fcc) position of the $\mathrm{Au}(111)$ surface was then studied, as a first approach towards determining how surface defects may affect the adsorption mode or energy of NHCs on $\mathrm{Au}$. Such low coordinated atoms are indeed expected to be the most reactive sites on the nanoparticle surface. ${ }^{[35]}$ In this case, only the adsorption of NHCa perpendicularly to the surface was looked into (see Model D in Figure 4). The binding of the carbene was found to be even more favourable energetically than in Model A ( -63.55 kcal.mol ${ }^{-1}$ vs $\left.\sim-34.21 \mathrm{kcal}^{\mathrm{mol}}{ }^{-1}\right)$. In Model D, no steric hindrance between the methyl groups and $\mathrm{Au}$ surface is observed, and after geometry optimization, the Au$\mathrm{C}(2)$ bond distance is $\sim 2.03 \AA$, which is shorter than what had been observed for Model A, and very similar to what is experimentally measured for $\mathrm{Au}-\mathrm{NHC}$ complexes. It is also worth noting that a similar adsorption energy $\left(\sim-67 \mathrm{kcal}^{\mathrm{mol}}{ }^{-1}\right)$ had been previously calculated for the binding of an imidazole-2ylidene bearing aryl bromide functional groups onto an adatom. ${ }^{[25]}$ On a more general perspective, the significant difference in adsorption energies of NHCa in Models A and D shows that the reactivity of the NHC will strongly depend on the gold surface structure. In view of analyzing in more detail the difference in affinity of NHCa for a variety of Au surface sites, we thus turned towards the modelling of its grafting onto smaller $\mathrm{Au}$ nanoparticles, which do not present any flat $\mathrm{Au}(111)$ surface.

Grafting of $\mathrm{NHCa}$ on a $\mathrm{Au}_{38}$ cluster. Many models of nanoparticles and/or small clusters of metals, metal oxides and metal chalcogenides have been theoretically investigated, ${ }^{[36]}$ including by some of us. ${ }^{[37]}$ Here, we decided to look into the adsorption of $\mathbf{N H C a}$ on the $\mathrm{Au}_{38}$ gold cluster, making the transition between the models of the defect free flat facet and the irregular surface of the AuNPs. The structure of the $\mathrm{Au}_{38}$ cluster was first created, starting from the crystallographic data of $\mathrm{Au}_{38}\left(\mathrm{SCH}_{2} \mathrm{CH}_{2} \mathrm{Ph}\right)_{24},{ }^{[38]}$ and performing a geometry optimization on the bare $\mathrm{Au}_{38}$ core. The equilibrium geometry is shown in Figure 5a: it consists of 2 central atoms (highlighted in Figure $5 \mathrm{~b}$ ) surrounded by an ellipsoidal 21 gold frame (highlighted in Figure $5 \mathrm{c}$ ), thereby forming an $\mathrm{Au}_{23}$ core. Finally, the remaining 15 gold atoms are located on some of the triangular faces of the $\mathrm{Au}_{23}$ core. The metallic core of the cluster (or the bare cluster) belongs to $\mathrm{a}_{3}$ point group within a $0.01 \AA$ tolerance
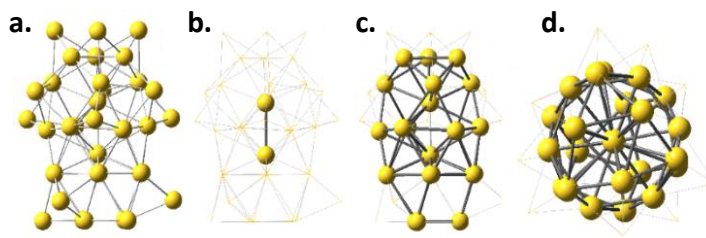

Figure 5. Equilibrium structures of the $\mathrm{Au}_{38}$ cluster at the DFT level (CAMB3LYP LANL2MB). a) the $\mathrm{Au}_{38}$ cluster; b) the two central atoms; c) the 23 gold core (2 central atoms $+21 \mathrm{Au}$ frame); d) the $\mathrm{Au}_{23}$ gold core visualized from the bottom.
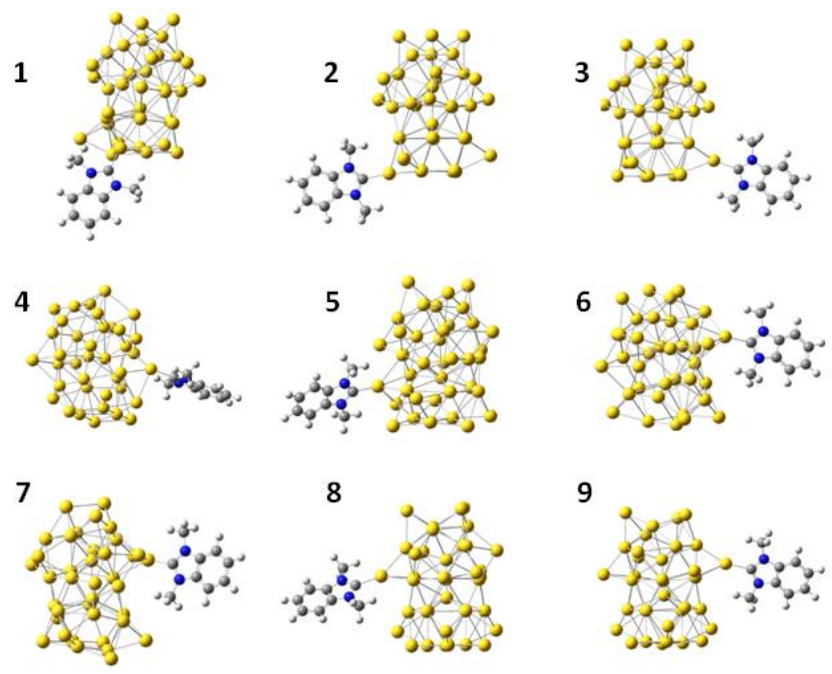

9
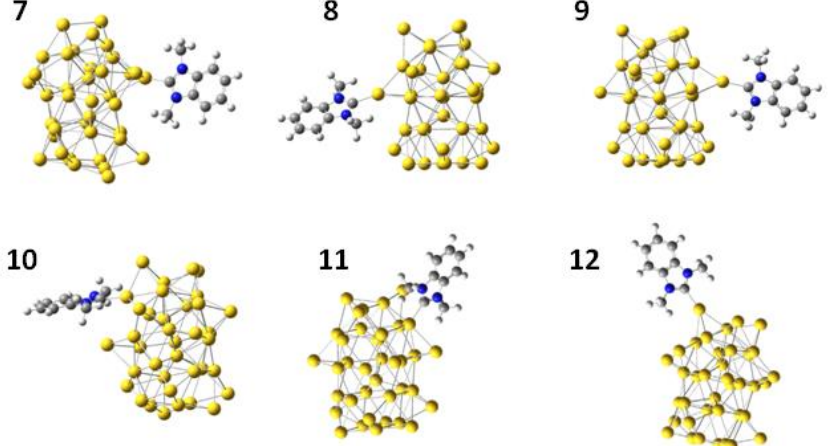

Figure 6. Equilibrium structures of the $\mathrm{NHCa}-\mathrm{Au}_{38}$ system, computed at the CAM-B3LYP LANL2MB/6-31G(d) level in the gas phase.

Natural bonding orbital (NBO) analyses show that the gold atoms of the bare cluster are separated in two differently charged populations (see the Supporting Information, Figure S13). In the first group, the partial charges were negative, 
varying from $-0.11 \mathrm{e} \mid$ to $-0.25 \mathrm{e} \mid$, with the $\mathrm{Au}_{23}$ gold core belonging to this group. The rest of the atoms (on the surface of the cluster) belonged to the second group, with positive partia charges ranging from $0.20|\mathrm{e}|$ to $0.29 \mathrm{|e}$. Further analyses of the natural charge of every atom showed that they followed the $\mathrm{C}_{3}$ symmetry, meaning that we could actually classify the 21 atoms of the $A_{21}$ shell frame and the 15 other atoms of the external surface in 12 different groups, each formed by 3 atoms possessing the same natural charge (see the Supporting Information, Figure S14)

Table 2. Complex label (as shown in Figure 6), coordination number $\mathrm{CN}^{[\mathrm{a}]}$ charge of the gold atom in the bare cluster (NBO Au bare), natural charge of the $\mathrm{Au}_{23}$ core $\left(\mathrm{NBO} \mathrm{Au}_{23}\right)$, binding energy $\left(\mathrm{BE}^{[\mathrm{b}]}\right)$, relative free energy $\Delta \mathrm{G}$ and $\mathrm{C}-\mathrm{Au}$ bond length of the $\mathrm{NHCa}-\mathrm{Au}_{38}$ system.

\begin{tabular}{|c|c|c|c|c|c|c|}
\hline$n^{\circ}$ & $\mathrm{CN}$ & $\begin{array}{l}\text { NBO Au } \\
\text { bare }(|\mathrm{e}|)\end{array}$ & $\begin{array}{c}\text { NBO } \\
\mathrm{Au}_{23}(|\mathrm{e}|)\end{array}$ & $\begin{array}{c}\text { BE } \\
\left(\mathrm{kcal}^{-1}\right. \\
\left.\mathrm{mol}^{-1}\right)\end{array}$ & $\begin{array}{c}\text { relat. } \Delta \mathrm{G} \\
(\mathrm{kcal} . \\
\mathrm{mol}^{-1} \text { ) }\end{array}$ & $\begin{array}{c}\text { C-Au } \\
(\AA)\end{array}$ \\
\hline 1 & 7 & -0.17 & -3.44 & -27.86 & 6.55 & 2.08 \\
\hline 2 & 4 & 0.23 & -3.15 & -33.48 & 0.92 & 2.09 \\
\hline 3 & 3 & 0.20 & -3.15 & -30.33 & 4.08 & 2.09 \\
\hline 4 & 8 & -0.11 & -2.82 & -29.59 & 4.82 & 2.08 \\
\hline 5 & 8 & -0.12 & -3.10 & -25.71 & 8.69 & 2.08 \\
\hline 6 & 7 & -0.22 & -3.00 & -34.41 & 0.00 & 2.08 \\
\hline 7 & 8 & -0.11 & -2.86 & -20.32 & 14.09 & 2.08 \\
\hline 8 & 3 & 0.29 & -3.15 & -34.38 & 0.02 & 2.09 \\
\hline 9 & 4 & 0.20 & -3.03 & -33.83 & 0.60 & 2.08 \\
\hline 10 & 8 & -0.14 & -3.04 & -19.51 & 14.90 & 2.08 \\
\hline 11 & 8 & -0.15 & -2.85 & -29.75 & 4.66 & 2.10 \\
\hline 12 & 3 & 0.23 & -3.08 & -34.27 & 0.14 & 2.08 \\
\hline
\end{tabular}

[a] $\mathrm{CN}$ is the coordination number of the gold atom in its bare configuration that interacts with the ligand. [b] $\mathrm{BE}$ represents the binding energy of the $\mathrm{Au}_{38}$ - NHC system. It is calculated as: $B E=\Delta G_{\text {complex }}-\Delta G_{\text {bare complex }}-n \Delta G_{\text {ligand }}$ where the $n$ is the number of ligands (in this case $n=1$ ).

One atom out of each of these 12 different partial charge groups was taken to interact with a single NHCa ligand. The equilibrium geometries are shown in Figure 6. Immediately, it appeared that completely different core geometries were obtained depending on the binding site of NHCa. Further analyses of the different equilibrium geometries showed that the $\mathrm{C}_{3}$ symmetry of the $\mathrm{Au}_{38}$ cluster was broken, and that in most cases the binding of NHCa "pulled" the gold atoms closer to each other within the cluster. This could be highlighted by comparing the distribution of distances between gold atoms in the bare $\mathrm{Au}_{38}$ and in the cluster ligated to $\mathrm{NHCa}$ (see the Supporting Information, Figures S15 and S16).
As shown in Table 2, in all cases, the NHC ligand was found to be strongly bound on the $\mathrm{Au}_{38}$ cluster surface, with binding energies ranging from -19.51 to $-34.41 \mathrm{kcal}^{\mathrm{mol}}{ }^{-1}$ (Table 2). Such binding energies are in the same range as those computed here on a flat $\mathrm{Au}(111)$ surface (between -11.42 and $34.21 \mathrm{kcal} . \mathrm{mol}^{-1}$, see Table 1), as well as with other previous DFT computations. ${ }^{[22,23]}$ Interestingly, the binding strengths varied with the binding site, being larger when $\mathrm{NHCa}$ was attached to the least coordinated gold atoms. This is in line with what had been observed for the VASP calculations, when comparing models with/without an adatom (Models A and D). The binding was found to be characterized by a charge transfer from the $\mathrm{NHCa}$ ligand to the $\mathrm{Au}_{23}$ core, with the natural charge of $\mathrm{Au}_{23}$ varying from -2.82 to $-3.44|\mathrm{e}|$ (Table 2). This clearly highlights the electron donor nature of NHC ligands. More specifically, as shown in Table 2, the natural charge on the $\mathrm{Au}_{23}$ core varied with the position of the grafted ligand, and the electron donor character of $\mathbf{N H C a}$ was enhanced when the coordination number of the gold atom (in its bare configuration) increased.

No significant difference was observed between the Au$\mathrm{C}(2)$ bond lengths of the 12 equilibrium structures, which varied between $\sim 2.08$ and $\sim 2.10 \AA$ (Table 2 ). Such values are slightly higher than the experimental value observed for the bis(NHC) $\mathrm{Au}(\mathrm{I})$ complex $\mathbf{3 a}$, but are in good agreement with previous DFT calculations of a single carbene adsorbed onto an $\mathrm{Au}(111)$ surface, ${ }^{[22,23]}$ such as those presented above (Table 1). In the most stable cases, the shortest $\mathrm{Au}-\mathrm{C}(2)$ bond length was $2.08 \AA$ for the $\mathrm{Au}_{38}$ cluster calculations (configuration 6 in Figure 6), and $2.03 \AA$ for the VASP calculations (Model D). The optimized geometries of the $\mathrm{NHCa}-\mathrm{Au}_{38}$ system were also analyzed by measuring angles between the $\mathrm{C}_{2}$ axis of $\mathrm{NHCa}$ and the $\mathrm{Au}_{38}$ cluster surface (see the Supporting Information, Figures S17 to S19). Among the 12 calculated configurations, different angles were observed between the gold cluster surface and $\mathbf{N H C a}$, especially when looking at the $\mathrm{C}_{2}$ axis of the ligand. In general, the NHC ligand was found to bind in an "on top" position on a tetrahedron formed by four gold atoms. Qualitatively, the configuration in which the ligand was the most perpendicular to the surface was configuration 3 in Figure 6 . However, no special relation could be found between the stability of the cluster and the angle of the ligand with respect to the cluster surface, nor with any other geometrical parameter

Having analyzed the mode of binding of one $\mathrm{NHC}$ on $\mathrm{Au}_{38}$, we then investigated the grating of more ligands at the nanoparticle surface. First, we looked at the effect of the addition a second $\mathrm{NHCa}$ on a surface $\mathrm{Au}$ site. The $\mathrm{NHCa}-\mathrm{Au}_{38}$ compound corresponding to configuration "6" (Figure 6) was used as starting point for this test, because this structure is the most stable energetically in the gas phase (Table 2 , entry 6 ), and a second NHCa was added on a neighbouring surface site. The final compound obtained after geometry optimization is shown in Figures $7 \mathrm{a}$ and $7 \mathrm{~b}$. Interestingly, the addition of a second ligand NHCa at this position did not induce a big distortion of the metallic core (see Figures S23 and S24). The equilibrium structure of the $\mathrm{Au}_{38}$ cluster fully covered by nine NHCa ligands was then computed in the gas phase (Figures $7 \mathrm{c}$ 
and 7d). Because of the electron donor character of the carbene ligands, the metallic core in $\mathrm{Au}_{38}(\mathrm{NHCa})_{9}$ has a negative charge of $-2.57|\mathrm{e}|$, see Figure S29. The larger negative charge on the metallic core leads to an increase of the Coulomb repulsion between the gold atoms and larger distances between $\mathrm{Au}$ atoms ranging from 2.67 to $12.27 \AA$, compared to 2.79 to $11.96 \AA$ for the bare cluster (see Figures S23 and S24). Overall, these calculations underscore the strong flexibility of the $\mathrm{Au}_{38}$ core upon coordination of $\mathrm{NHC}$ ligands as simple as $\mathrm{NHCa}$ at its surface. a.

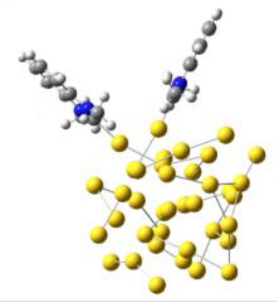

c.

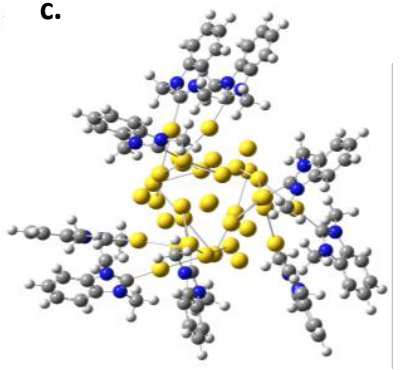

b.

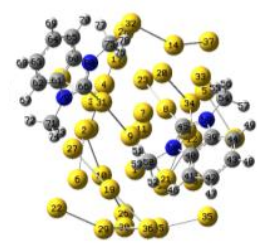

d.

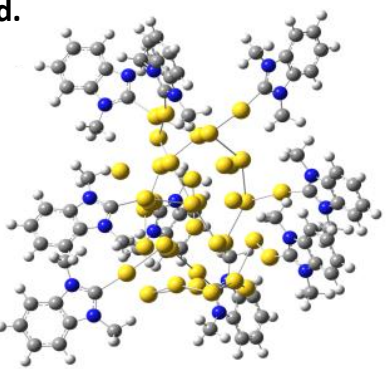

Figure 7. Equilibrium structures of the $(\mathrm{NHCa})_{2}-\mathrm{Au}_{38}$ system with two ligands $\mathrm{NHCa}$ close to each other computed at the CAM-B3LYP LANL2MB/6-31G(d) level in the gas phase: a) Top view, b) Side view. Equilibrium structures of the $(\mathrm{NHCa})_{9}-\mathrm{Au}_{38}$ system computed at the same level: c) Top view, d) Side view.

Possible mechanism to explain the formation of bis(NHC) Au(l) complexes. By combining experimental and theoretical data, we propose as a first approximation the following mechanism to explain the formation of bis(NHC) $\mathrm{Au}(\mathrm{I})$ complexes and NHC grafted AuNPs (Figure 8):

(1) At the initial state, the weakly adsorbed thioethers are gradually substituted by strongly bonded NHCs. The binding energies can be high (exceeding $-34 \mathrm{kcal}_{\mathrm{mol}}{ }^{-1}$, according to DFT calculations) and do not seem depend on the size of the AuNPs, because they are similar for both systems where NHCs are bound to a $\mathrm{Au}(111)$ surface (assimilated to the surface of a large $\mathrm{AuNP}$ ) or to $\mathrm{a} \mathrm{Au}_{38}$ cluster-type surface (assimilated to a small AuNP)

(2) Although computational studies show that the binding energy between NHCs and AuNPs surface is high enough to ensure their stability, the absence of secondary interactions (such as van der Waals interactions) between NHCa-c can explain the poor stability of obtained AuNPs. The strength of the $\mathrm{NHC}-\mathrm{Au}$ bonds leads to a repositionning of the $\mathrm{Au}$ atom with respect to the surface and to surface reconstruction, with the formation of surface defects like Au adatoms on the AuNP.
Subsequently, the NHC-Au moiety may diffuse at the AuNP surface, and/or reconstruct the surface, ${ }^{[22]}$ because the $\mathrm{C}$-Au bonds compete with the Au-Au bonds.

(3) Finally, the (mono)NHC-Au fragments released from the surface can react with the remaining $\mathrm{NHC}$ ligands in solution, by analogy with what has been observed previously with other types of ligands such as phosphines ${ }^{[39]}$ leading to the formation of bis $(\mathrm{NHC}) \mathrm{Au}(\mathrm{I})$ complexes and thereby to the erosion of the AuNPs. Surface reconstruction leading to etching is a commonly observed phenomenon with thiol coating agents. ${ }^{[40]}$

If characterizing molecular species such as bis(NHC) $\mathrm{Au}(\mathrm{I})$ complexes is easy by using routine techniques such as ${ }^{13} \mathrm{C}$ NMR spectroscopy, more difficulties were encountered when characterizing nanomaterials. In this context, calculating ${ }^{13} \mathrm{C}$ NMR spectra of NHC-coated AuNPs would be particularly useful to understand how ${ }^{13} \mathrm{C}$ NMR signals of $\mathrm{NHC}$ ligands are altered upon ligation to the Au surface.

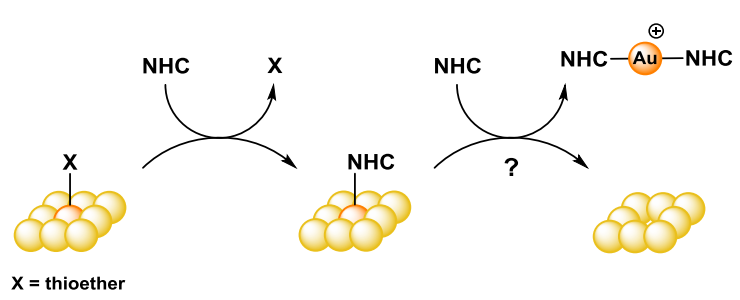

Figure 8. Proposed steps for the formation of bis(NHC) $A u(I)$ complexes by reaction of NHCs with AuNPs. The AuNP surface is schematically represented here, and the Au atom removed from AuNP surface is drawn in orange.

Calculation of ${ }^{13} \mathrm{C}$ NMR spectra of $\mathrm{NHCa}$ bound to $\mathrm{Au}_{38}$ clusters. NMR spectroscopy is a uniquely-suited technique to characterize molecular species present at the surface of MNPs, and to determine the presence of different surface sites. ${ }^{[41]}$ Most of the time, spectral differences are observed between the "attached" molecular species and their "free" form, such as a line broadening or disappearance of some resonances, and/or altered chemical shifts, because the local environment of the surface-bound molecules is different and more diverse than in solution. ${ }^{[37]}$ Given the difficulties we had encountered in characterizing the NHCa-functionalized AuNPs by $\mathrm{NMR}^{\left[{ }^{[23]}\right.}$ we decided to use DFT calculations to determine how ${ }^{13} \mathrm{C}$ NMR signals of NHCa might have been altered upon ligation to the AuNP surface, such information being useful for future studies of the grafting of other carbenes onto AuNP surfaces (Table 3).

The ${ }^{13} \mathrm{C}$ NMR chemical shifts of molecular complex 3a were calculated in a polarizable continuum model (PCM) mimicking the effect of DMSO- $d_{6}$ as solvent, with and without the $\mathrm{BF}_{4}^{-}$counter anion. Results obtained for the cation showed a good agreement between the calculated and the experimental chemical shifts of complex $\mathbf{3 a}$, although all calculated signals were found at slightly higher chemical shifts (Table 3 , see also Figure S26 and Table S10 in the Supporting Information). In particular, the calculated chemical shift of the carbene atom of complex $3 a$ is $\delta=191.54 \mathrm{ppm}$, which is close to the experimental value $(\delta=190.19 \mathrm{ppm})$. Taking into account the 
$\mathrm{BF}_{4}^{-}$anion in the computation of the NMR spectrum leads to a much better agreement with the experimental data, except in the case of the lowest chemical shift as can be seen in Figure S26 and in Table S10.

Table 3. Experimental and calculated ${ }^{13} \mathrm{C}$ NMR chemical shifts $\delta$ (ppm) and chemical shift differences $\Delta \delta$ for the carbene and $\mathrm{N}-\mathrm{Me}$ group resonances.)

\section{Carbene / $\delta(\mathrm{ppm})^{[\mathrm{a}]} \quad \mathrm{N}-\mathrm{Me} / \delta(\mathrm{ppm})^{[\mathrm{a}]}$}

Experimental

$\begin{array}{ccc}\mathbf{2} \mathbf{a}^{[\mathrm{b}]} & 177.18 & 34.91 \\ \mathbf{3} \mathbf{a}^{[\mathrm{b}]} & 190.19 & 34.84 \\ \text { AuNP(a) } & 180(4)^{[\mathrm{c}]} & \end{array}$

\section{Calculated}

$$
\begin{gathered}
2 \mathbf{a}^{[e]} \\
3 \mathbf{a}\left(-\mathrm{BF}_{4}\right)^{[\mathrm{e}, g]}
\end{gathered}
$$$$
189.64(1)^{[f]}
$$$$
37.16(2)^{[f]}
$$

$$
3 \mathbf{a}^{[\mathrm{e}, \mathrm{h}]}
$$

$$
191.54(1)^{[f]}
$$$$
36.89(2)^{[t]}
$$

$\mathrm{NHC}_{\mathrm{a}}-\mathrm{Au}_{38}(6)^{[\mathrm{e}, \mathrm{i}]}$ $192.29-191.40(2)^{[f]}$

$30.14-29.27(4)^{[f]}$

$\mathrm{NHC}_{\mathrm{a}}-\mathrm{Au}_{38}(2)^{[\mathrm{e}, \mathrm{j}]}$

$\left(\mathrm{NHC}_{\mathrm{a}}\right)_{2}-\mathrm{Au}_{38}{ }^{[\mathrm{e}]}$

$189.62(1)^{[f]}$

$36.35-32.81(2)^{[f]}$

$187.33(1)^{[\mathrm{f}]}$

$33.61-32.68(2)^{[\mathrm{f}]}$

$\left(\mathrm{NHC}_{\mathrm{a}}\right)_{9}-\mathrm{Au}_{38}{ }^{[\mathrm{e}]}$

$190.10-188.16(2)^{[\mathrm{f}]}$

$36.07-32.71(4)^{[f]}$

$36.01-30.72(18)^{[f]}$

[a] The $\delta$ ranges represent the lowest and the highest chemical shifts in ppm. [b] Measured in DMSO- $d_{6}$, see reference [23]. [c] Measured at the solid state, see reference [23]. [d] Number in parentheses corresponds to the full width at half maximum. [e] Calculated at the CAM-B3LYP level in DMSO- $d_{6}$. Tetramethylsilane (TMS) was used as ${ }^{13} \mathrm{C}$ NMR reference. [ $f$ ] Numbers in parentheses represent the number of signals calculated for a given configuration. [g] Calculated for complex $3 \mathbf{a}$ without $\mathrm{BF}_{4}^{-}$anion. [h] Calculated for complex $3 \mathrm{a}$ with $\mathrm{BF}_{4}^{-}$anion. [i] Calculated for configuration 6 in Figure 6. [j] Calculated for configuration 2 in Figure 6.

To calculate the ${ }^{13} \mathrm{C}$ NMR chemical shifts of NHCa ligated to an AuNP surface, we used the $\mathrm{NHCa}-\mathrm{Au}_{38}$ compound corresponding to configuration " 6 " in Figure 6 , this structure being the most stable energetically in the gas phase (Table 2 , entry 6). In order to be able to compare the calculated shifts for the $\mathbf{N H C a}-\mathrm{Au}_{38}$ model with those of the molecular complexes $\mathbf{3 a}$, the equilibrium geometry of the $\mathrm{NHCa}-\mathrm{Au}_{38}$ cluster was first optimized in a polarizable continuum model mimicking the effect of DMSO- $d_{6}$ as solvent (see the Supporting Information, Figures S20-S22). Compared to the gas phase structure shown in Figure 6 , only small differences were observed after geometry optimization in the solvent model: while $\mathrm{Au}-\mathrm{C}(2)$ bond lengths were close to $2.08 \AA$ in both cases, a slight decrease in the charge of the $\mathrm{Au}_{23}$ core was observed $(-3.00|\mathrm{e}|$ in the gas phase compared to $-2.89|\mathrm{e}|$ charge in the presence of the DMSO- $d_{6}$ ). As expected, calculated ${ }^{13} \mathrm{C}$ NMR signals for this $\mathrm{NHCa}-\mathrm{Au}_{38}$ cluster were split because the NHC carbon atoms become nonequivalent at the AuNP surface (Table 3, and Figure S27 and Table S7 in the Supporting Information), the most important split being obtained for the two methyl groups $(\Delta \delta=3.54 \mathrm{ppm})$. It is also noticeable that all calculated ${ }^{13} \mathrm{C}$ NMR signals of NHCa$\mathrm{Au}_{38}$ cluster were found at lower chemical shifts compared to those calculated for complex 3a (Table 3, and Table S10 in the Supporting Information). Indeed, the calculated chemical shift of the carbene atom ligated to the $\mathrm{Au}_{38}$ cluster was $\delta=189.62 \mathrm{ppm}$, which is still in the range of those observed for NHC-Au complexes. The location of $\mathrm{NHCa}$ on the $\mathrm{Au}_{38}$ cluster has no significant effect, since calculated ${ }^{13} \mathrm{C}$ NMR signals of $\mathrm{NHCa}$ $\mathrm{Au}_{38}$ cluster in configuration "2" in Figure 6 are similar to those calculated in configuration " 6 " (Table 3 and Table S7 in the Supporting Information).

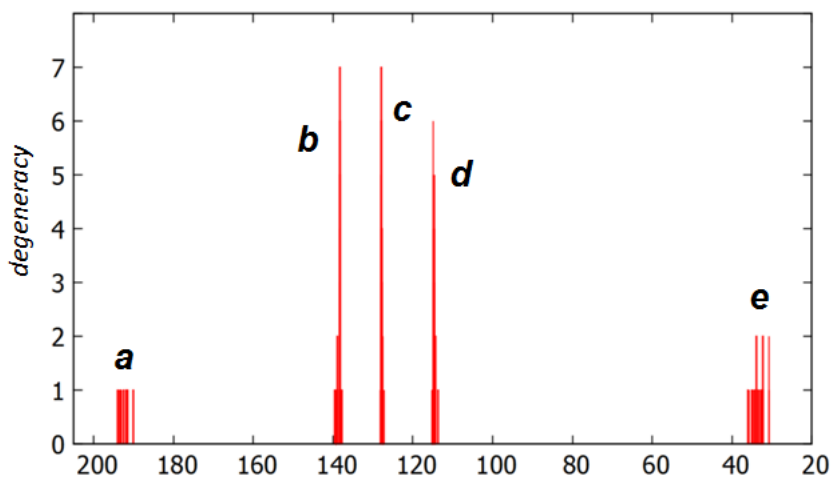<smiles></smiles>
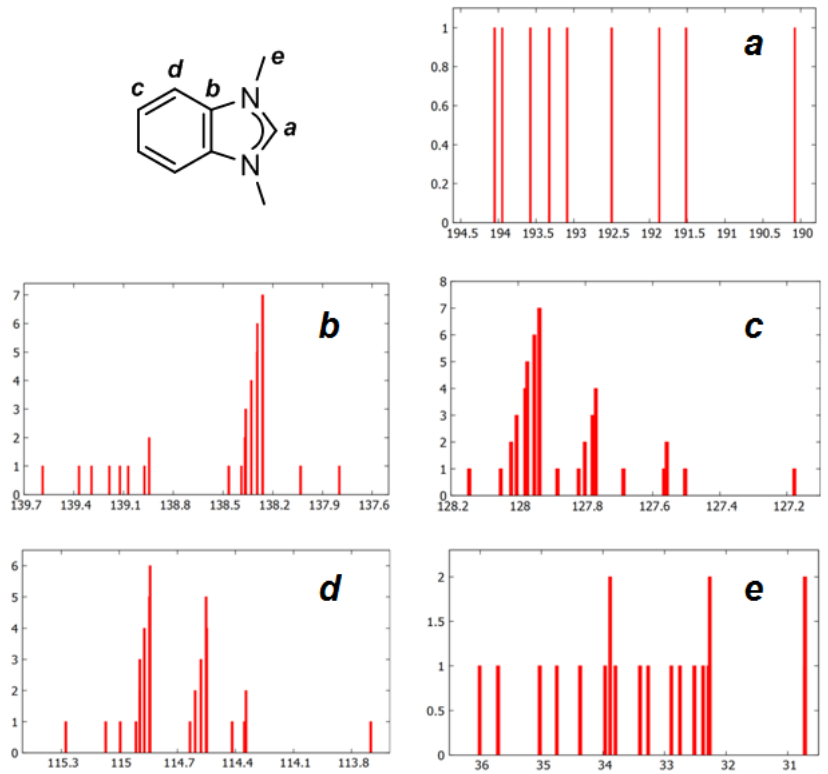

$\delta / \mathrm{ppm}$

Figure 9. Calculated ${ }^{13} \mathrm{C}$ NMR spectrum of the $(\mathbf{N H C a})_{9}-\mathrm{Au}_{38}$ system in DMSO- $d_{6}$. TMS (tetramethylsilane) was used as ${ }^{13} \mathrm{C}$ NMR reference. All calculations have been performed at the DFT CAM-B3LYP level of theory. The relativistic pseudopotential and basis set LANL2MB were used in the case of gold while for the other atoms $6-311+G(2 d, p)$ was employed. 
Adding an extra NHCa close to the first one (as in Figures $7 \mathrm{a}$ and $7 \mathrm{~b}$ ) had a significant impact on the computed NMR spectrum (Table 3, $\left.(\mathbf{N H C a})_{2}-\mathrm{Au}_{38}\right)$. Indeed, all signals were split, due to the fact that each $\mathrm{NHCa}$ ligand experienced different chemical environments (Figure S28 and Table S8 in the Supporting Information). This is even more noticeable in the case of the fully protected $(\mathbf{N H C a})_{9}-\mathrm{Au}_{38}$ cluster (Figures $7 \mathrm{c}$ and $7 \mathrm{~d}$ ), as shown by the range of calculated ${ }^{13} \mathrm{C}$ NMR chemical shifts for each type of $\mathrm{C}$ atom (shown in Figure 9 and Table 3, and Table S9 in the supporting Information). Nevertheless, it is worth underscoring that for both the $(\mathbf{N H C a})_{2}-\mathrm{Au}_{38}$ and $(\mathbf{N H C a})_{9}-\mathrm{Au}_{38}$ models, the average values of calculated chemical shifts for each type of carbon are similar, even for the $\mathrm{C}$ atom of the carbene (Table S10 in the Supporting Information).

Although these NMR calculations are the first of the kind to be carried out on models of NHC-functionalized AuNPs, and thus provide an interesting guideline to the discussion of experimental spectra, comparisons to available ${ }^{13} \mathrm{C}$ NMR data are still difficult to perform. The broadening of the NMR signals of the grafted NHCs can be clearly explained by looking at the study of the $(\mathbf{N H C a})_{9}-\mathrm{Au}_{38}$ model, but it is more difficult to discuss the changes in chemical shifts (especially of the $\mathrm{C}$ atom of the carbene). ${ }^{[23]}$ This is due to the fact that calculations here were performed on a simple $\mathrm{NHCa}$ ligand grafted on "small" $\mathrm{Au}_{38}$ clusters, while experimental systems involve in general (i) more complex ligands (with different ligand-ligand interactions) and/or other sizes of particles (between $\sim 1$ and $6.8 \mathrm{~nm}$ ), as well as (ii) different analytical conditions (solid vs. solution NMR...). Unfortunately, the complete modelling such complex systems is still computationally prohibitive at this stage.

\section{Conclusions}

Many studies reported so far had shown that strong C-Au bonds are formed in the course of the formation of NHC-coated

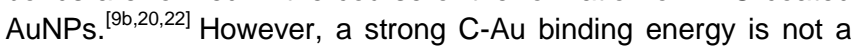
sufficient factor to ensure the stability of NHC-coated AuNPs. Here, for example, we performed a ligand exchange reaction between NHC ligands (benzimidazol-2-ylidenes) and thioethercoated AuNPs and observed the formation of bis(NHC) $\mathrm{Au}(\mathrm{I})$ complexes, as well as the formation of smaller aggregated AuNPs. The decrease in size of the AuNPs and the formation of molecular of bis(NHC) $\mathrm{Au}(\mathrm{I})$ complexes could be explained by the poor ability of benzimidazol-2-ylidenes used here to stabilize AuNPs.

Further details on the reactivity of NHCs at the surface of AuNPs were reached by combining experiments to computational modeling. The development of two types of computational models of the Au surface was found to be particularly useful, in order to be able to confirm the calculated trends and to generalize the conclusions to different sizes of nanoparticles. Calculations of NMR shifts were performed for the first time on these systems, showing that they can be used as an interesting guideline to discuss experimental spectra. Nevertheless, several challenges remain at this stage, which include (i) recording higher-sensitivity ${ }^{13} \mathrm{C}$ NMR spectra of functionalized AuNPs (using for example techniques like Dynamic Nuclear Polarization), ${ }^{41 \mathrm{~b}}$ (ii) developing more realistic computational models (involving notably more complex NHCs), and performing spectroscopic calculations on these complex models (such as NMR) in order to confront them with the experimental data.

\section{Experimental Section}

\section{Materials}

Reactions were performed using oven-dried glassware. Chemicals were obtained from Alfa-Aesar $\left(\mathrm{HAuCl}_{4} \cdot 3 \mathrm{H}_{2} \mathrm{O}\right.$, benzimidazole, di- $n$ dodecylsulfide, benzyl bromide), Sigma-Aldrich $\left(\mathrm{AgBF}_{4}\right)$, Panreac $\left(\mathrm{NaBH}_{4}\right)$ and Lancaster (tetra- $n$-octylammonium bromide), and used as received. The $N, N$-dibenzylbenzimidazolium bromide precursor, the AuNPs functionalized by di- $n$-dodecylsulfide, and complex $2 \mathrm{c}$ were synthesized as described in the supporting information. All reactions were monitored by thin-layer chromatography using Merck@ TLC Silica gel 60 F254 plates. ${ }^{1} \mathrm{H}$ and ${ }^{13} \mathrm{C}\left\{{ }^{1} \mathrm{H}\right\}$ solution NMR spectra were recorded in $\mathrm{DMSO}-d_{6}$ on a Bruker $300 \mathrm{MHz}$ spectrometer. Chemical shifts are reported in ppm, referenced to DMSO solvent residual peak at $2.50 \mathrm{ppm}$ for ${ }^{1} \mathrm{H}$, and $39.52 \mathrm{ppm}$ for ${ }^{13} \mathrm{C}\left\{{ }^{1} \mathrm{H}\right\}$. Abbreviations for ${ }^{1} \mathrm{H}$ NMR spectra used are as follows: s, singlet; $d$, doublet; $t$, triplet; qt, quintuplet; $\mathrm{m}$, multiplet. ESI mass spectra were recorded on a Q-Tof Waters 2001 MS spectrometer.

\section{Synthesis}

$\mathrm{N}, \mathrm{N}$-dibenzylbenzimidazolium tetrafluoroborate salt (1c). $\mathrm{N}, \mathrm{N}$ dibenzylbenzimidazolium bromide $(0.280 \mathrm{~g}, 0.738 \mathrm{mmol})$ was dissolved in acetonitrile $(25 \mathrm{~mL})$. A solution of $\mathrm{AgBF}_{4}(0.158 \mathrm{~g}, 0.812 \mathrm{mmol})$ in acetonitrile $(5 \mathrm{~mL})$ was then added dropwise leading to the precipitation of $\mathrm{AgBr}$. The suspension was stirred for 16 hours in absence of light and the precipitate was eliminated by filtration. The filtrate was evaporated to dryness, and the white residue was dissolved in dichloromethane. The solution was heated to reflux for several minutes, and then, filtered to remove insoluble impurities. The filtrate was concentrated to reach a volume of $\sim 2 \mathrm{~mL}$, and $n$-pentane was then added, leading to the immediate formation of a precipitate. After filtration and several washings with $n$-pentane, the benzimidazolium salt was isolated as a white solid $(89 \%, 0.250 \mathrm{~g}) .{ }^{1} \mathrm{H}$ NMR (300 MHz, DMSO- $\left.\boldsymbol{d}_{6}, \mathbf{2 5}^{\circ} \mathrm{C}\right): \delta 10.02(\mathrm{~s}, 1 \mathrm{H}$, $\mathrm{C}(2)-\mathrm{H}), 7.97\left(\mathrm{dd},{ }^{3} \mathrm{~J}_{\mathrm{H}-\mathrm{H}}=6.2 \mathrm{~Hz},{ }^{4} \mathrm{JH}_{\mathrm{H}-\mathrm{H}}=3.1 \mathrm{~Hz}, 2 \mathrm{H}, \mathrm{H}_{\mathrm{Ar}}\right), 7.63\left(\mathrm{dd},{ }^{3} \mathrm{~J}_{\mathrm{H}-\mathrm{H}}\right.$ $\left.=6.2 \mathrm{~Hz},{ }^{4} J_{\mathrm{H}-\mathrm{H}}=3.1 \mathrm{~Hz}, 2 \mathrm{H}, \mathrm{H}_{\mathrm{Ar}}\right), 7.58-7.32\left(\mathrm{~m}, 10 \mathrm{H}, \mathrm{H}_{\mathrm{Ar}}\right), 5.79(\mathrm{~s}, 4 \mathrm{H}$, $\left.\mathrm{CH}_{2}\right)$ ppm ${ }^{13} \mathrm{C}\left\{{ }^{1} \mathrm{H}\right\}$ NMR $\left(75.4 \mathrm{MHz}\right.$, DMSO-d $\left.\boldsymbol{d}_{6}, \mathbf{2 5}^{\circ} \mathrm{C}\right): \delta 142.7(\mathrm{C}(2))$, $133.9\left(\mathrm{C}_{\mathrm{Ar}}\right), 131.1\left(\mathrm{C}_{\mathrm{Ar}}\right), 129.0\left(\mathrm{C}_{\mathrm{Ar}}\right), 128.8\left(\mathrm{C}_{\mathrm{Ar}}\right), 128.3\left(\mathrm{C}_{\mathrm{Ar}}\right), 126.8\left(\mathrm{C}_{\mathrm{Ar}}\right)$ $114.0\left(\mathrm{C}_{\mathrm{Ar}}\right), 50.0\left(\mathrm{CH}_{2}\right)$ ppm HRMS (ESI-TOF $\left.{ }^{+}\right)$: calcd for $\mathrm{C}_{21} \mathrm{H}_{19} \mathrm{~N}_{2}{ }^{+}[\mathrm{M}]^{+}$: $\mathrm{m} / \mathrm{z}=299.1548$, found: 299.1549 .

Crude $\operatorname{AuNPs}(\mathbf{C})$ : To a toluene solution $(12 \mathrm{~mL})$ of di- $n$-dodecylsulfideprotected AuNPs, the $\mathrm{N}, \mathrm{N}$-dibenzylbenzimidazolium tetrafluoroborate salt 1c $(0.198 \mathrm{~g}, 0.512 \mathrm{mmol})$ was added, followed by $\mathrm{NaOtBu}(0.086 \mathrm{~g}$, $0.895 \mathrm{mmol}$ ). The mixture was stirred for 16 hours in absence of light. Then, absolute $\mathrm{EtOH}(50 \mathrm{~mL})$ was added and the mixture was refrigerated at $4^{\circ} \mathrm{C}$ for two hours. After that, a dark precipitate was separated by centrifugation (10.000 rpm for 5 minutes). After removing the supernatant, absolute $\mathrm{EtOH}(15 \mathrm{~mL})$ was added and centrifugation was performed. This washing procedure was repeated twice. Finally, the insoluble crude AuNPs were collected with $n$-pentane $(10 \mathrm{~mL})$ and the solvent was slowly evaporated under atmospheric pressure at room 
temperature. After drying under vacuum, crude $\operatorname{AuNPs}(\mathbf{C})$ were obtained as a violet solid.

\section{Separation of bis( $N, N$-dibenzylbenzimidazol-2-ylidene $) \mathrm{Au}(\mathrm{I})$ tetrafluoroborate complex 3c from crude AuNPs(C): Acetonitrile (20 $\mathrm{mL}$ ) was added to the insoluble crude $\operatorname{AuNPs}(\mathbf{C})$ and the mixture was sonicated for 2 minutes. After centrifugation (10.000 rpm, 5 minutes), the supernatant was separated from the solid residue of $\operatorname{AuNPs(C).~This~}$ procedure was repeated three times. The organic phases were then filtered through celite and evaporated together to dryness. $n$-pentane (10 $\mathrm{mL}$ ) was added to the solid residue and the mixture was filtered and dried under vacuum. The complex was obtained as a white solid in $38 \%$ yield (45 mg). ${ }^{1} \mathbf{H}$ NMR (300 MHz, DMSO- $\left.\boldsymbol{d}_{6}, \mathbf{2 5}^{\circ} \mathbf{C}\right): \delta 7.82\left(\mathrm{dd},{ }^{3} J_{\mathrm{H}-\mathrm{H}}=6.0 \mathrm{~Hz}\right.$, $\left.{ }^{4} J_{\mathrm{H}-\mathrm{H}}=3.0 \mathrm{~Hz}, 4 \mathrm{H}, \mathrm{H}_{\mathrm{Ar}}\right) 7.75\left(\mathrm{dd},{ }^{3} J_{\mathrm{H}-\mathrm{H}}=6.2 \mathrm{~Hz},{ }^{4} J_{\mathrm{H}-\mathrm{H}}=3.0 \mathrm{~Hz}, 4 \mathrm{H}, \mathrm{H}_{\mathrm{Ar}}\right)$, $\delta 7.46\left(\mathrm{dd},{ }^{3} \mathrm{~J}_{\mathrm{H}-\mathrm{H}}=6.1 \mathrm{~Hz},{ }^{4} \mathrm{~J}_{\mathrm{H}-\mathrm{H}}=3.0 \mathrm{~Hz}, 4 \mathrm{H}, \mathrm{H}_{\mathrm{Ar}}\right) 7.40\left(\mathrm{dd},{ }^{3} \mathrm{~J}_{\mathrm{H}-\mathrm{H}}=6.1 \mathrm{~Hz}\right.$ $\left.{ }^{4} \mathrm{~J}_{\mathrm{H}-\mathrm{H}}=3.1 \mathrm{~Hz}, 4 \mathrm{H}, \mathrm{H}_{\mathrm{Ar}}\right), 7.37-7.19\left(\mathrm{~m}, 2 \mathrm{H}, \mathrm{H}_{\mathrm{Ar}}\right), 5.82\left(\mathrm{~s}, 8 \mathrm{H}, \mathrm{CH}_{2}\right), 5.75$ (s, $8 \mathrm{H}, \mathrm{CH}_{2}$ ) ppm. The ${ }^{1} \mathrm{H}$ NMR spectrum is actually complex (see ESI), due to the existence of an equilibrium in solution. HRMS (ESI-TOF ${ }^{+}$): calcd for $\mathrm{C}_{42} \mathrm{H}_{36} \mathrm{~N}_{4} \mathrm{Au}^{+}[\mathrm{M}]^{+}: \mathrm{m} / z=793.2605$, found: 793.2609 .}

TEM and SEM images. Samples for transmission electron microscopy (TEM) measurements were prepared by deposition of a drop of crude AuNPs(C) suspension on a copper grid. TEM measurements were carried out at $100 \mathrm{kV}$ using a JEOL 1200 EXII microscope. Scanning electron microscopy measurements (SEM) were conducted on a Hitachi S4800 instrument. Powdered samples were simply deposited on double face tape and then, Pt-metallized by sputtering under vacuum.

Powder XRD analyses. Powder XRD analyses were carried out on a Philips X'pert Pro MPD diffractometer using Cu Ka1 radiation $(\lambda=1.5406$ $\AA$ ) in Bragg-Brentano scanning mode with a $2 \theta$ angle range from 4 to $40^{\circ}$ (or 4 to $53^{\circ}$ ), and a time per step of 50 or $300 \mathrm{~s}$, depending on the sample.

Solid state NMR. All solid state NMR experiments were performed on a Varian VNMRS $600 \mathrm{MHz}$ (14.1 T) NMR spectrometer, using a $1.6 \mathrm{~mm}$ Varian T3 HXY MAS probe. The operating frequencies for ${ }^{13} \mathrm{C}$ was 150.83 MHz. Temperature regulation was used during the experiments, to avoid any heating of the sample over $25^{\circ} \mathrm{C}$ during the spinning. ${ }^{1} \mathrm{H}-{ }^{13} \mathrm{C}$ CPMAS NMR spectra were recorded spinning at 25 or $30 \mathrm{kHz}$, using a contact time of $2.5 \mathrm{~ms}$, and $100 \mathrm{kHz}$ spinal- $64{ }^{1} \mathrm{H}$ decoupling during acquisition. The recycle delays and number of transients acquired were adapted for each sample, as shown in Table S5 (see the Supporting Information). ${ }^{13} \mathrm{C}$ chemical shifts were referenced externally to adamantane (used as a secondary reference), the high frequency peak being set to $38.5 \mathrm{ppm}$

\section{Computational details}

Periodic DFT calculations. Calculations were performed in the frame of periodic DFT by means of the Vienna Ab Initio Simulation Package (VASP). ${ }^{[29]}$ The electron-ion interactions were described by the projector augmented wave $(\mathrm{PAW})^{[42]}$ method, representing the valence electrons, as provided in the code libraries. The convergence of the plane-wave expansion was obtained with a cut off of $500 \mathrm{eV}$. The generalized gradient approximation (GGA) was used with the functional of PerdewBurke-Ernzerhof (PBE). ${ }^{[43]}$ The sampling in the Brillouin zone was performed on the gamma point.

Since our system involves organic molecules in interaction, we introduced dispersion forces, by using the Grimme D2 method ${ }^{[4]}$ as implemented in VASP 5.2.11. DFT-D2 Grimme (G, D2) describes the van der Waals interactions between an atom and its neighbors in a given radius, via a simple pair-wise force field. This force field is optimized for several popular DFT functionals. In this case, this operator takes one atom as a reference one, and calculates the interactions of this atom with those around until a given distance or radius, and the same is done for all the atoms of the system. The calculated dispersion energy is then added to the pure DFT energy: $E=E_{\mathrm{DFT}}+E_{\mathrm{D} 2}$

The $A u(111)$ surface was modeled as a slab containing 3 layers of gold The slab was cut out of the bulk face centered cubic cell of Au. This slab size was chosen by careful evaluation of the quality/costs ratio, after satisfactory convergence tests of the system. In the periodic DFT calculations, the surface is infinite in two dimensions, with a vacuum space in the $z$ axis direction. In our calculations, the vacuum layer was about $20 \AA$ length along z, which was found to be large enough to enable the adsorption of $\mathrm{NHCa}$, while preventing its interaction with the consecutive repetitions of the unit cell. The bulk optimized cell parameter $a$ after optimization of the slab at the PBE level was found to be equal to $4.164 \AA$, which is in good agreement with the experimental data (4.078 $\AA)$ for face centered cubic cell of gold. ${ }^{[45]}$ For the slab the unit cell parameter was equal to $\mathrm{a}=2.94 \AA$

During geometry optimizations of grafted surfaces, the bottom layer in the Au slab was kept frozen on the bulk positions, while the two others were allowed to relax. The structure of the ligands and complexes adsorbed at the surface of the slab in the different models were allowed to fully relax during the geometry optimizations. The adsorption energy $\Delta \mathrm{E}_{\text {ads }}$ of $\mathrm{NHCa}$ on the $\mathrm{Au}(111)$ surface was calculated as follows: $\Delta \mathrm{E}_{\mathrm{ads}}=$ $E_{\mathrm{Au}^{-} \mathrm{NHCa}}-E_{\mathrm{Au}}-E_{\mathrm{NHCa}}$ (eq. 1), where $E_{\mathrm{Au}-\mathrm{NHC}}$ is the energy of the complete system (after geometry optimization), $E_{A u}$ is the energy of the gold slab (after geometry optimization, alone) and $\mathrm{E}_{\mathrm{NHCa}}$ is the energy of the $\mathrm{NHCa}$ carbene (after geometry optimization, alone)

DFT calculations on the $\boldsymbol{A u}_{38}$ cluster. All computations on the $\mathrm{Au}_{38}$ cluster were carried out at the density functional level of theory as implemented in Gaussian 09 program. $^{[31]}$ The long-range corrected functional CAM-B3LYP ${ }^{[46]}$ was used together with the LANL2MB relativistic corrected pseudopotentials and basis sets ${ }^{[47,48]}$ for the gold atoms and the $6-31 G(d)$ Gaussian basis set for the carbene ligand. Frequency calculations on the equilibrium geometries showed no imaginary frequencies for all the reported structures. Natural population analysis and natural bond orbital methodologies ${ }^{[49,50]}$ were used to compute the partial charges on the atoms of the clusters. Contributions from different fragments $\left(\mathrm{Au}_{23}\right.$ core, the surface atoms and the ligand) to the frontier molecular orbitals were obtained with AOMix program ${ }^{[51,52]}$ using the default MPA (Mulliken population analysis). Evaluation of the solvent $\left(\mathrm{DMSO}-d_{6}\right)$ effect on the structure of the single carbene $\mathrm{NHCa}$ ligated $\mathrm{Au}_{38}$ cluster was performed using the polarizable continuum model $(\mathrm{PCM})^{[53,54]}$ Nuclear magnetic resonance (NMR) spectra were computed using the CAM-B3LYP functional together with the LANL2MB relativistic corrected pseudopotentials and basis sets for the gold atoms and the $6-311+G(2 d, p)$ Gaussian basis set for the carbene ligand.

\section{Acknowledgements}

This work was supported by the University of Montpellier and the CNRS. We are grateful to the Labex "CheMISysT" program (ANR-10-LABX-05-01) for financial support of Dr. M. R.-C. The HINT COST action MP1202 is acknowledged for support. The periodic DFT calculations were performed using HPC resources from GENCI- [CCRT/CINES/IDRIS] (Grant 2013-[x2013082022]) and the CCRE of Université Pierre et Marie Curie. Dr. B. 
Diawara from ENS Paris is kindly acknowledged for providing us with ModelView used in the visualization of the structures. G. L. thanks IDS FUNMAT for a PhD fellowship. G. L. and F. R. gratefully acknowledge access to the computational resources of CECl (Consortium des Equipements de Calcul Intensif). F. R. thanks Fonds National de la Recherche Scientifique (Belgium) for its support.

\section{Keywords: carbene $\bullet$ nanoparticles $\bullet$ gold $\bullet$ surface $\cdot$ DFT}

[1] a) A. Balanta, C. Godard, C. Claver, Chem. Soc. Rev., 2011, 40, 4973; b) A. Schatz, O. Reiser, W. J. Stark, Chem. Eur. J. 2010, 16, 8950; c) N. Yan, C. Xiao, Y. Kou, Coord. Chem. Rev. 2010, 254, 1179; d) M. Stratakis, H. Garcia, Chem. Rev. 2012, 112, 4469; e) M. Pagliaro, V. Pandarus, R. Ciriminna, F. Béland, P. Demma Carà, ChemCatChem 2012, 4, 432; f) A. Boullanger, S. Clément, V. Mendez, S. Daniele, C. Thieuleux, A. Mehdi, RSC Advances 2013, 3, 725.

[2] a) E. Boisselier, D. Astruc, Chem. Soc. Rev. 2009, 38, 1759; b) B. Duncan, C. Kim, V. M. Rotello, J. Contr. Release 2010, 148, 122; c) L. Vigderman, E. R. Zubarev, Adv. Drug. Deliver. Rev. 2013, 65, 663; d) A. A. Sousa, J. T. Morgan, P. H. Brown, A. Adams, P. Mudiyanselage, G. Zhang, C. J. Ackerson, M. J. Kruhlak, R. D. Leapman, Small 2012, 8 2277; e) K. Huang, H. Ma, J. Liu, S. Huo, A. Kumar, T. Wei, X. Zhang, S. Jin, Y. Gan, P. C. Wang, S. He, X. Zhang, X.-J. Liang, ACS Nano 2012, 6, 4486; f) X. Wu, X. He, K. Wang, C. Xie, B. Zhou Z. Qing, Nanoscale 2010, 2, 2244

[3] a) R. Sardar, A. M. Funston, P. Mulvaney, R. W. Murray, Langmuir, 2009, 25, 13840; b) P. Alexandritis, Chem. Eng. Technol. 2011, 34, 15 c) P. Zhao, N. Li, D. Astruc, Coord. Chem. Rev., 2013, 257, 638.

[4] a) W. A. Herrmann, C. Köcher, Angew. Chem. Int., Ed. Engl. 1997, 36, 2162; b) D. Bourissou, O. Guerret, F. P. Gabbaie, G. Bertrand, Chem. Rev. 2000, 100, 39; c) W. A. Herrmann, Angew. Chem., Int. Ed. 2002 41, 1290; d) F. Glorius, Top. Organomet. Chem. 2007, 21, 1; e) E. A. B. Kantchev, C. J. O'Brien, M. G. Organ, Angew. Chem., Int. Ed. 2007, 46, 2768; f) S. Wuertz, F. Glorius, Acc. Chem. Res. 2008, 41, 1523; g) F. E. Hahn, M. C. Jahnke, Angew. Chem., Int. Ed. 2008, 47, 3122; h) B. Alcaide, P. Almendros, A. Luna, Chem. Rev. 2009, 109, 3817; i) S. Díez-González, N. Marion, S. P. Nolan, Chem. Rev. 2009, 109, 3612; j) G. C. Fortman, S. P. Nolan, Chem. Soc. Rev. 2011, 40, 5151.

[5] a) M. Yoshimura, R. Kamisue, S. Sakaguchi, S, J. Organomet. Chem. 2013, 740, 26; b) L. J. L. Häller, M. J. Page, S. Erhardt, S; A. Macgregor, M. F. Mahon, M. A. Naser, A. Velez, M. K. Whittlesey, J. Am. Chem. Soc. 2010, 132, 18408; c) A. R. Naziruddin, C.-S. Zhuang, W.-J. Lin, W.-S. Hwang, Dalton Trans. 2014, 43, 5335.

[6] a) J. Yang, P. Li, Y. Zhang, L. Wang, Dalton Trans. 2014, 43, 7166; b) T. A. P. Paulose, S.-C. Wu, J. W. Quail, S. R. Foley, Inorg. Chem. Commun. 2012, 15, 37; c) B. Karimi, P. F. Akhavan, Inorg. Chem. 2011 50, 6063 .

[7] a) S. Gaillard, P. Nun, A. M. Z. Slawin, S. P. Nolan, Organometallics 2010, 29, 5402; b) R. Visbal, A. Laguna, M. C. Gimeno, Chem. Commun. 2013, 49, 5642.

[8] Niemeier, A. Henseler, Chem. Rev. 2007, 107, 5606; c) N. Marion, S. Díez-González, S. P. Nolan, Angew. Chem., Int. Ed. 2007, 46, 2988; d) N. E. Kamber, W. Jeong, R. M. Waymouth, R. C. Pratt, B. G. G. Lohmeijer, J. L. Hedrick, Chem. Rev. 2007, 107, 5813; e) V. Nair, S. Vellalath, B. P. Babu, Chem. Soc. Rev. 2008, 37, 2691; f) A. J. Arduengo III, L. I. Iconaru, Dalton Trans. 2009, 6903; g) V. Nair, R. S. Menon, A. T. Biju, C. R. Sinu, R. R. Paul, A. Jose, S. Vellalath, Chem. Soc. Rev. 2011, 40, 5336; h) A. T. Biju, N. Kuhl, F. Glorius, Acc. Chem. Res. 2011, 44, 1182; (i) M. Fèvre, J. Pinaud, Y. Gnanou, J. Vignolle, D. Taton, Chem. Soc. Rev. 2013, 42, 2142; j) J.-F. Lefebvre, M. Lo, J.-P. Gisselbrecht, O. Coulembier, S. Clément, S. Richeter, Chem. Eur. J. 2013, 19, 15652.
[9] a) K. V. S. Ranganath, J. Kloesges, A. H. Schäfer, F. Glorius, Angew. Chem. Int. Ed. 2010, 49, 7786; b) C. Richter, K. Schaepe, F. Glorius, B. J. Ravoo, Chem. Commun. 2014, 50, 3204; c) A. Ferry, K. Schaepe, P. Tegeder, C. Richter, K. M. Chepiga, B. J. Ravoo, F. Glorius, ACS Catal. 2015, 5, 5414.

[10] X. Ling, N. Schaeffer, S. Roland, M.-P. Pileni, Langmuir, 2013, 29 12647.

[11] a) P. Lara, O. Rivada-Wheelaghan, S. Conejero, R. Poteau, K Philippot, B. Chaudret, Angew. Chem. Int. Ed. 2011, 50, 12080; b) D. Gonzalez-Galvez, P. Lara, O. Rivada-Wheelaghan, S. Conejero, B. Chaudret, K. Philippot, P. W. N. M. van Leeuwen, Catal .Sci. Technol. 2013, 3, 99.

[12] a) P. Lara, A. Suarez, V. Collire, K. Philippot, B. Chaudret ChemCatChem 2014, 6, 87; b) E. A. Baquero, S. Tricard, J. C. Flores, E. de Jesus, B. Chaudret, Angew. Chem. Int. Ed. 2014, 53, 13220.

[13] a) M. Brust, M. Walker, D. Bethell, D. Schiffrin, R. Whyman, J. Chem. Soc., Chem. Commun. 1994, 801; b) A. C. Templeton, W. P. Wuelfing, R. W. Murray, Acc. Chem. Res. 2000, 33, 27; c) R. Schenhar, V. M. Rotello, Acc. Chem. Res. 2003, 36, 549.

[14] a) A. G. Kanaras, F. S. Kamounah, K. Schaumburg, C. J. Kiely, M. Brust, Chem. Commun. 2002, 2294; b) T. Peterle, P. Ringler, M. Mayor, Adv. Funct. Mater. 2009, 19, 3497; c) T. Peterle, A. Leifert, J. Timper, A. Sologubenko, U. Simon, M. Mayor, Chem. Commun. 2008, 3438.

[15] a) R. Sharma, G. P. Holland, V. C. Solomon, H. Zimmermann, S. Schiffenhaus, S. A. Amin, D. A. Buttry, J. L. Yarger, J. Phys. Chem. C, 2009, 113, 16387; b) H. Zhang, G. Schmid, U. Hartmann, Nano Lett. 2003, 3, 305; c) L. F. Chi, M. Hartig, T. Drechsler, T. Schwaack, C Seidel, H. Fuchs, G. Schmid, G. Appl. Phys. A 1998, 66, 187.

[16] a) Y. G. Kim, S.-K. Oh, R. M. Crooks, Chem. Mater. 2004, 16, 167; b) Y Chen, Y.-M. Zhang, Y. Liu, Chem. Commun. 2010, 46, 5622.

[17] J. Turkevitch, P. C. Stevenson, J. Hillier, Discuss. Faraday Soc. 1951 11, 55.

[18] J. Vignolle, T. D. Tilley, Chem. Commun. 2009, 7230.

[19] X. Ling, S. Roland, M. P. Pileni, Chem. Mater. 2015, 27, 414.

[20] J. Crespo, Y. Guari, A. Ibarra, J. Larionova, T. Lasanta, D. Laurencin, J. M. Lopez-de-Luzuriaga, M. Monge, M. E. Olmos, S. Richeter, Dalton Trans. 2014, 43, 15713.

[21] E. C. Hurst, K. Wilson, I. J. S. Fairlamb, V. Chechik, New J. Chem, 2009, 33, 1837.

[22] C. M. Crudden, J. H. Horton, I. I. Ebralidze, O. V. Zenkina, A. B McLean, B. Drevniok, Z. She, H.-B. Kraatz, N. J. Mosey, T. Seki, E. C. Keske, J. D. Leake, A. Rousina-Webb, G. Wu, Nat. Chem. 2014, 6, 409

[23] M. Rodríguez-Castillo, D. Laurencin, F. Tielens, A. Van der Lee, S. Clément, Y. Guari, S. Richeter, Dalton Trans. 2014, 43, 5978.

[24] a) S. G. Song, C. Satheeshkumar, J. Park, J. Ahn, T. Prekumar, Y. Lee, C. Song, Macromolecules 2014, 47, 6566; b) M. J. MacLeod, J. Johnson, J. Am. Chem. Soc. 2015, 137, 7974.

[25] a) T. Doneux, F. Tielens, P. Geerlings, C. Buess-Herman, J. Phys Chem. A. 2006, 110, 11346; a) A. V. Zhukhovitskiy, M. G. Mavros, T. V. Voorhis, J. A. Johnson, J. Am. Chem. Soc. 2013, 135, 7418.

[26] a) I. Favier, S. Massou, E. Teuma, K. Philippot, B. Chaudret, M. Gómez, Chem. Commun. 2008, 3296; b) T. Doneux, F. Tielens, P. Geerlings, C. Buess-Herman, J. Phys. Chem. A 2006, 110, 11346.

[27] X.-M. Li, M. R. de Jong, K. Inoue, S. Shinkai, J. Huskens, D. N Reinhoudt, J. Mater. Chem. 2001, 11, 1919.

[28] S. Guo, H. Sivaram, D. Yuan, H. V. Huynh, Organometallics 2013, 32, 3685.

[29] A. S. Barnard, X. M. Lin, L. A. Curtiss, J. Phys. Chem. B 2005, 109 24465.

[30] H. Qian, W. T. Eckenhoff, Y. Zhu, T. Pintauer, R. Jin, J. Am. Chem. Soc 2010, 132, 8280-8281.

[31] Gaussian 09, Revision D.01, M. J. Frisch, G. W. Trucks, H. B. Schlegel, G. E. Scuseria, M. A. Robb, J. R. Cheeseman, G. Scalmani, V. Barone, B. Mennucci, G. A. Petersson, H. Nakatsuji, M. Caricato, X. Li, H. P. Hratchian, A. F. Izmaylov, J. Bloino, G. Zheng, J. L. Sonnenberg, M. 
Hada, M. Ehara, K. Toyota, R. Fukuda, J. Hasegawa, M. Ishida, T. Nakajima, Y. Honda, O. Kitao, H. Nakai, T. Vreven, J. A. Montgomery Jr., J. E. Peralta, F. Ogliaro, M. Bearpark, J. J. Heyd, E. Brothers, K. N. Kudin, V. N. Staroverov, R. Kobayashi, J. Normand, K. Raghavachari, A. Rendell, J. C. Burant, S. S. Iyengar, J. Tomasi, M. Cossi, N. Rega, J. M. Millam, M. Klene, J. E. Knox, J. B. Cross, V. Bakken, C. Adamo, J. Jaramillo, R. Gomperts, R. E. Stratmann, O. Yazyev, A. J. Austin, R. Cammi, C. Pomelli, J. W. Ochterski, R. L. Martin, K. Morokuma, V. G. Zakrzewski, G. A. Voth, P. Salvador, J. J. Dannenberg, S. Dapprich, A D. Daniels, Ö. Farkas, J. B. Foresman, J. V. Ortiz, J. Cioslowski, and D. J. Fox, Gaussian, Inc., Wallingford CT, 2009.

[32] D. Mollenhauer, N. Gaston, E. Voloshina, B. Paulus, J. Phys. Chem. C 2013, 117, 4470

[33] H. M. J. Wang, C. Y. L. Chen, I. J. B. Lin, Organometallics 1999, 18 1216.

[34] E. Bedford, V. Humblot, C. Méthivier, F. Gu, C.-M. Pradier, F. Tielens, S. Boujday. Chem.Eur.J. 2015, 21, 14555.

[35] a) T. V. W. Janssens, B. S. Clausen, B. Hvolbaek, H. Falsig, C. H. Christensen, T. Bligaard, J. K. Norskov, J. K. Top. Catal. 2007, 44, 15 b) A. Corma, M. Boronat, S. González, F. Illas, Chem. Commun, 2007 3371; c) L. M. Molina, B. Hammer, Appl. Catal. A-Gen. 2005, 291, 21 d) J. L. C. Fajín, M. N. D. S. Cordeiro, J. R. B. Gomes, Catalysts 2011 1, 40-51; e) N.B. Luque, E. Santos, J. Andres, F. Tielens, Langmuir 2011, 27, 14514.

[36] a) A. Fernando, K. L. D. M. Weerawardene, N V. Karimova, C. M. Aikens, Chem. Rev. 2015, 115, 6112; b) B. Zhu, I. C. Oğuz, H. Guesmi, J. Chem. Phys. 2015, 143, 144309

[37] a) F. Tielens, J. Andrés, J. Phys. Chem. C 2007, 111, 10342; b) B. Fresch, F. Remacle, , J. Phys. Chem. C 2014, 118, 9790; c) G. Lugo, V. Schwanen, B. Fresch, F. Remacle, J. Phys. Chem. C, 2015, 119, 10969.

[38] a) G. Kresse, J. Hafner, Phys. Rev. $B$ 1993, 48, 13115; b) G. Kresse, J. Hafner, J. Phys.-Condens. Matter, 1994, 6, 8245.
[39] a) R. Sharma, G. P. Holland, V. C. Solomon, H. Zimmermann, S Schiffenhaus, S. A. Amin, D. A. Buttry and J. L. Yarger, J. Phys. Chem C, 2009, 113, 16387.

[40] a) C Vericat, M. E. Vela, G. Benitez, P. Carro, R. C Salvarezza, Chem. Soc. Rev. 2010, 39, 1805; b) C. Schonenberger, J. A. M. Sondag Huethorst, J. Jorritsma, L. G. J. Fokkink, Langmuir 1994, 10, 611.

[41] a) E. A. Baquero, S. Tricard, J. C. Flores, E. de Jesús, B. Chaudret, Angew. Chem. Int. Ed. 2014, 53, 13220; b) C. Bonhomme, C. Gervais D. Laurencin, Prog. Nucl. Mag. Res. Sp. 2014, 77, 1; c) L. E. Marbella J. E. Millstone, Chem. Mater. 2015, 27, 2721; c) L. M.Martinez-Prieto, A Ferry, P. Lara, C. Richter, K. Philippot, F. Glorius, B. Chaudret, Chem. Eur. J. 2015, 21, 17495; d) J. Cure, Y. Coppel, T. Dammak, P. F. Fazzini, A. Mlayah, B. Chaudret, P. Fau, Langmuir 2015, 31, 1362.

[42] a) P. E. Blochl, Phys. Rev. B 1994, 50, 17953; b) G. Kresse, D. Joubert, Phys. Rev. B 1999, 59, 1758

[43] a) J. P. Perdew, K. Burke, M. Ernzerhof, Phys. Rev. Lett. 1996, 77 , 3865; b) J. P. Perdew, K. Burke, M. Ernzerhof, Phys. Rev. Lett. 1997, $78,1396$.

[44] S. Grimme, J. Comput. Chem. 2006, 27, 1787

[45] A. Maeland, T. B. Flanagan, Can. J. Phys. 1964, 42, 2364.

[46] T. Yanai, D. P. Tew, N. C. Handy, Chem. Phys. Lett. 2004. 393, 51

[47] P. J. Hay, W .R. Wadt, J. Chem. Phys. 1985, 82, 299.

[48] P. J. Hay, W. R. Wadt, J. Chem. Phys. 1985, 82, 270.

[49] A. E. Reed, L. A. Curtiss, F. Weinhold, Chem. Rev. 1988, 88, 899.

[50] J. P. Foster F. Weinhold, J. Am. Chem. Soc. 1980, 102, 7211.

[51] S. I. Gorelsky, A.B.P. Lever, J. Organomet. Chem. 2001, 635, 187

[52] S. I. A. Gorelsky, Program for Molecular Orbital Analysis; Version 6.X. Uniersity of Ottawa, 2013.

[53] J. Tomasi, B. Mennucci, R. Cammi, Chem. Rev. 2005, 105, 2999.

[54] E. Cancès, B. Mennucci, J. Tomasi, J. Chem. Phys. 1997, 107, 3032. 